\title{
Mapping the Social Class Structure From Occupational Mobility to Social Class Categories Using Network Analysis
}

Toubøl, Jonas; Grau Larsen, Anton

Document Version

Accepted author manuscript

Published in:

Sociology

DOI:

$10.1177 / 0038038517704819$

Publication date:

2017

License

Unspecified

Citation for published version (APA):

Toubøl, J., \& Grau Larsen, A. (2017). Mapping the Social Class Structure: From Occupational Mobility to Social Class Categories Using Network Analysis. Sociology, 51(6), 1257-1276.

https://doi.org/10.1177/0038038517704819

Link to publication in CBS Research Portal

\section{General rights}

Copyright and moral rights for the publications made accessible in the public portal are retained by the authors and/or other copyright owners and it is a condition of accessing publications that users recognise and abide by the legal requirements associated with these rights.

Take down policy

If you believe that this document breaches copyright please contact us (research.lib@cbs.dk) providing details, and we will remove access to the work immediately and investigate your claim. 


\title{
Mapping the Social Class Structure: From Occupational Mobility to Social Class Categories Using Network Analysis Jonas Toubol and Anton Grau Larsen
}

Journal article (Post print version)

\author{
Jonas Toubøl and Anton Grau Larsen, Mapping the Social Class Structure: From \\ Occupational Mobility to Social Class Categories Using Network Analysis, Sociology \\ (Vol. 51, No. 6) pp. 1257-1276. \\ Copyright [? [२०17] (The Authors). \\ Reprinted by permission of SAGE Publications.
}

DOI: 10.1177/0038038517704819

Uploaded to Research@CBS: February २०17 


\title{
Mapping the social class structure: From occupational mobility to social class categories using network analysis
}

\begin{abstract}
This article develops a new explorative method for deriving social class categories from patterns of occupational mobility. In line with Max Weber, our research is based on the notion that, if class boundaries do not inhibit social mobility then the class categories are of little value. Thus, unlike dominant, theoretically defined class schemes, this paper derives social class categories from observed patterns in a mobility network covering intragenerational mobility. The network is based on a mobility table of 109 occupational categories tied together by 1,590,834 job shifts on the Danish labour market 2001-07. The number of categories are reduced from 109 to 34 by applying a new clustering algorithm specifically designed for the study of mobility tables (MONECA). These intra-generational social class categories are related to the central discussions of gender, income, education, and political action by providing empirical evidence of strong patterns of intra-generational class divisions along these lines.
\end{abstract}

\section{Keywords}

Class analysis, cluster analysis, intra-generational social mobility, Methodology, MONECA, social network analysis, Social class, Class theory, occupational mobility

\section{Authors}

Jonas Toubøl, University of Copenhagen, Department of Sociology

Anton Grau Larsen, Copenhagen Business School, Department of Business and Politics

\section{Corresponding author}

Jonas Toubøl, University of Copenhagen, Department of Sociology, Øster Farimagsgade 5, Bld. 16, DK-1014 Copenhagen K, Denmark, jt@soc.ku.dk

\section{Introduction}

This article proposes a new methodology for identifying class boundaries on the basis of a network of mobility between occupations. By deriving the class structure from mobility patterns we are able to stay closer to the theoretical ambition in Weberian class analysis, in which mobility between classes should be rare. This new method therefore contributes to the question of mapping the class structure which have preoccupied sociologists for more than a century (Marx and Engels, 2008 [1848]; Weber, 1978 [1922]). The questions of class boundaries and the correct empirical delimitation of classes are central to this debate. The problem of class boundaries is posed either as a question of the empirical operational outcome of competing class theories (Goldthorpe, 2007; Wright, 2005), as a question of the categories designed to tests various hypotheses about the structure of social mobility (e.g. Blau and Duncan, 1967; Clogg and Goodman, 1984) or as a question of the relative delimitation of clusters of individuals sharing tastes and dispositions (Bourdieu, 1987). Lately, this debate has changed profoundly, as the relevance of class theory, and indeed the very existence of classes has been brought into question (Pakulski, 2005).

Grusky, Weeden, and associates have set out to reconstruct class analysis by focusing on the realistic occupational categories expressing the division of labour as the site of production of class based behaviour and mobility patterns (Weeden and Grusky, 2005, 2012). What is at stake in this long running debate (Erikson et al., 2012; Grusky and Weeden, 2002) is whether class is best explained on the basis of 88 micro-classes (Jonsson et al., 2009), 11 meso-classes (Erikson and Goldthorpe, 1993) or 12 relational classes (Wright, 1989). Such theoretically derived class schemes are the most prominent, but they have been challenged by more data sensitive and descriptive approaches (Savage et al., 2013, 2015). 
In the descriptive tradition, this study will demonstrate the viability of a data sensitive approach that derives intra-generational class structure from the mobility patterns between occupations. This is achieved by applying a new clustering algorithm, the Mobility Network Clustering Algorithm (MONECA), which we have developed ${ }^{1}$ to register-data drawn from official records covering the entire Danish working population in the period 2001-2007. The result is 34 social classes reflecting the intra-generational social mobility structure. This result can be characterized as a mix of meso- and micro-classes, suggesting that the Danish intra-generational social class structure is not captured by any of the dominant universal class schemes. Rather, analyses of the distribution of income, education, political action and gender indicates that no single factor alone can account for the intragenerational social class structure revealed. This suggests that future research should investigate how different factors in different ways are involved in the formation of the various social classes of the intra-generational mobility structure.

Irrespective of how different theories have derived class boundaries, a common assumption is that these barriers also represent barriers to social mobility. Indeed, social mobility is at the very heart of class analysis. The power of class as an analytical concept consists in its ability to reflect that members of society cannot easily leave their class position. This entails that those sharing a class position will tend to perceive, and act upon the world in similar ways because their lives are conditioned by the same inescapable structures (Giddens, 1973). In truth, unless they are accompanied by barriers to mobility, class boundaries are only academic abstractions of little practical importance. The profound relation between social mobility and class finds an early and clear formulation in Max Weber's famous descriptive definition of social class: "A "social class" makes up the totality of those class situations within which individual and generational mobility is easy and typical.' (Weber, 1978: 302 [1922]). While both Giddens and Weber place barriers to mobility at the core of their class theory, neither of them had methods that allowed mobility to define class boundaries. This article hopes to provide such a methodology.

None of today's dominant class schemes take their starting point in the observation of social mobility. The class schemes mentioned above all start from theoretical considerations about class formation, while mobility only plays a role as a, however privileged, variable to test the class schemes. Bourdieu starts from a theory of distinction, but his approach is more empirically sensitive and identifies classes by empirical analysis of latent dimensions or fields (Bourdieu, 1984). However, no observation of patterns of mobility are included in determining the class categories (Andersen and Hansen, 2012; Wacquant, 2013). The same is the case with the CAMSIS-scale, based on observed social interaction patterns of friendship and marriage (Prandy and Lambert, 2003; Stewart et al., 1980). If we acknowledge the fundamental weakness of any class scheme which does not reflect actual barriers to social mobility, the contemporary lack of such schemes challenges us to develop a method by which we can derive a class scheme from the observation of social mobility patterns between occupations. Such a description of the mobility structure will allow us to aggregate occupations into the proper classes within which mobility is easy and typical, and thereby to ground our class scheme solidly in the problem of mobility.

In this paper we conceptualise the mobility table as a network of occupations tied together by the social mobility between the occupational categories. We develop an exploratory method that clusters together the occupations in order to derive the intra-generational social class structure. In the following section we elaborate on the intrinsic relationship between class and the structure of mobility in the tradition of class-analysis. We argue that, in order to advance class-analysis, we need to approach the empirical analysis of classes and their boundaries in a descriptive way, as opposed to a purely explanatory strategy based on statistical model-testing. We then move on to the main contribution, namely, the new analytical method we propose. Subsequently, we apply the method to Danish register-data and analyse 1,590,834 job shifts which took place between 2001 and 2007. After presenting the results, we discuss certain methodological issues and the resulting social class categories in relation to the factors of gender, income, education, and political action. Finally, we present our conclusions. 


\section{Class and mobility structure}

For students of social mobility, Weber's above-quoted definition of a social class constitutes an important starting point. Weber makes two points: First, intra- as well as inter-generational mobility is constitutive of social class. Inter-generational mobility has received much attention, but in this paper we are going to analyse intragenerational mobility. This should suffice, because the purpose of this paper is to present and demonstrate our method's ability to overcome the problem of identifying class boundaries. Furthermore, intra-generational mobility has received relatively little attention in the literature on class, and this study contributes to countering this bias. It does imply, however, that the results should not be directly compared to analyses of intergenerational mobility. Different dynamics are at play in the two forms of mobility, which warrants separating the analyses of the two forms of mobility and their class structure. We therefore also hesitate to make direct comparisons to class schemes like those mentioned above, which, even though they may claim to also encompass intra-generational mobility, are often constructed in relation to inter-generational mobility.

Weber's second, and more crucial point is that social class is made up of patterns of "easy and typical" mobility. Theoretically speaking, a mobility pattern refers to the transition from one position in the economy to another. When operationalised empirically, mobility pattern typically means movement from one occupation to another. The logic of Weber's definition further suggests that analysis of mobility patterns should be the starting point for the empirical investigation of the social class structure.

Giddens rephrases and specifies Weber's definition of social classes as '[...] a cluster of class situations which are linked together by virtue of the fact that they involve common mobility chances, either within the career of individuals or across the generations.' (1973: 48). What we develop in this paper is precisely a method, which can identify such "clusters of class situations" based on the observed patterns of mobility at a highly disaggregated level. Also, following Giddens, we separate the question of intra- and inter-generational mobility, and focus on the former. This represents a deviation from Weber who tended to conflate the two forms of mobility. An even more operationalized definition, alluding to social network analysis (SNA), can be found in Breiger's summary of Blau, Duncan and Giddens' Weberian perspective: ‘[...] classes are essentially sociometric "cliques” defined so that mobility chances [...] are higher within the cliques than between them' (Breiger, 1981: 584).

The logic of Weber's definition of social class suggests an approach in which description is prior to explanation. In order to investigate the mechanisms generating boundaries to mobility, i.e. explain social classes, we must first identify the exact location of the social class boundaries. To use the concepts of Giddens, we must carefully describe the class based structure of social mobility in order to investigate the structuration of social mobility. Following this logic, Giddens underscores that ' $[\ldots]$ the existence of distinct class 'boundaries' $[\ldots]$ ' cannot be '[...] settled in abstracto', because the class structuration of various societies ' $[\ldots]$ differs significantly according to variations in economic and political development' (Giddens, 1973: 110).

Hence, what is needed is a detailed description of the social class structure, understood as a number of occupational clusters within which mobility is relatively high and between which mobility is relatively low. Such a description will provide the structure that is to be explained. The explanatory effort should take its point of departure in investigation of the identified boundaries. This would enable examining the mechanisms and processes generating the barriers to mobility.

An argument supporting this claim has been provided by Savage et al. (2013) who, echoing Giddens, argue that the need for descriptive and exploratory methods has been accentuated by the growing realization that no single class scheme fits all societies. Rather, if uncritically applied such universal class schemes may be misleading because they make us blind to significant differences between societies, and explanations related to specific societies may be overlooked. This is due to both ' $[\ldots]$ real cross-nation differences with respect to qualification levels, job autonomy, career prospects (i.e. social mobility), organization of production, etc.' (Savage et al., 2013: 223) and the multi-dimensionality of social stratification. In our perspective, multi-dimensionality means that the mobility barriers generating the social mobility structure may consist of a variety of processes and mechanisms of 
selection. This implies that, rather than excluding the impact of factors such as gender, age, institutions, cultural norms, ethnicity, etc. on mobility, they are perceived as potential drivers of class formation.

For instance, if a social class turns out to be the result of mobility patterns created by young people enrolled in education who work part-time jobs in the service sector and often change jobs, this is not a problem, but a result in the sense that the existence of this social class is explained by a specific position in the economy tied to age. An example of such a finding is provided in the case of the Emergent service workers identified by Savage et al. (2013: 240ff.). Following this logic, also such factors as e.g. gender-based division of labour may give rise to barriers to job-mobility constitutive of social classes. Such a descriptive and exploratory approach implies that, in the subsequent mapping of the Danish intra-generational social class structure, we do not, a priori, exclude or seek to control for any number of factors that according to a given theory of class are considered extra-class.

The descriptive concept of social class does, of course, relate to class theory, but the distinction is crucial as the concept of social class does not imply a theory of its formation as opposed to the class-concept of a class theory. Thus, several social classes may be combined into one class due to theoretical explanation. For instance, if unskilled workers are separated into different social classes the separate social classes may together constitute a class of unskilled workers. Thus, social classes should be viewed as the building blocks or segments that constitute the starting point for the operationalization of a class theory into a class scheme. However, the social classes impose limitations on the construction of classes. The salience of mobility barriers to class boundaries implies that if a class theory suggests splitting a social class (within which mobility is easy and typical) into different classes, the validity of the class scheme will be undermined. This is due to the permeability of the class boundaries resulting from the split.

\section{The mobility table as network}

This study relates to the inductive tradition of research on class and stratification with the occupational mobility table at the centre (Breiger, 1981; Goodman, 1981; Klatzky and Hodge, 1971; Levine, 1972; MacDonald, 1972). However, this study diverts in two ways. First, we focus on intra- and not inter-generational mobility. Second, most scholars in this tradition have aimed at identifying the dimensions driving mobility and have often based their models on scales of the occupational hierarchies (E.g. Duncan, 1961; Treiman, 1977). This study instead aims at describing the intra-generational social class structure in an exploratory manner.

In order to correctly delimit the mobility categories in a descriptive way, we conceptualize the occupational mobility table as a network of occupations. This has been done before by e.g. Grifftihs and Lambert (2012), although they analysed marriage-relations and not social mobility. Occupations take the form of nodes in the network and the individuals' mobility between occupations generates the ties. From such a mapping we can observe between which occupations the labour force flows freely and between which occupations barriers appear to disrupt the flow of labour. The next step is quite literally to identify the " $[. .$.$] essentially sociometric "cliques"$ [...]' (Breiger, 1981: 584) that constitute the social class categories of the mobility structure.

The ties connecting the nodes are measured as the relative risk (RR). RR expresses the relative likeliness of the occurrence of job shifts from one occupation to another. $R R=1$ represents the ideal situation of 'perfect' mobility. The straight forward translation of the RR into a measure of the intensity (or weight) of a network tie would be that if $R R \geq 1$ there is a tie between the nodes. If $R R<1$ the nodes are not connected. We can now depict the intra-generational mobility on the Danish labour market in the period 2001-2007 as a directed weighted network which is done in figure 1. Later we present the data used to construct the network. The size of the nodes expresses a logarithmic function of the size of the occupational category. The colour of the nodes expresses degree of internal mobility. The darker the node, the closer to 100\% internal mobility. The alpha of the colour of the edges expresses the intensity of the mobility flow. 
Figure 1. Intra-generational occupational mobility as network

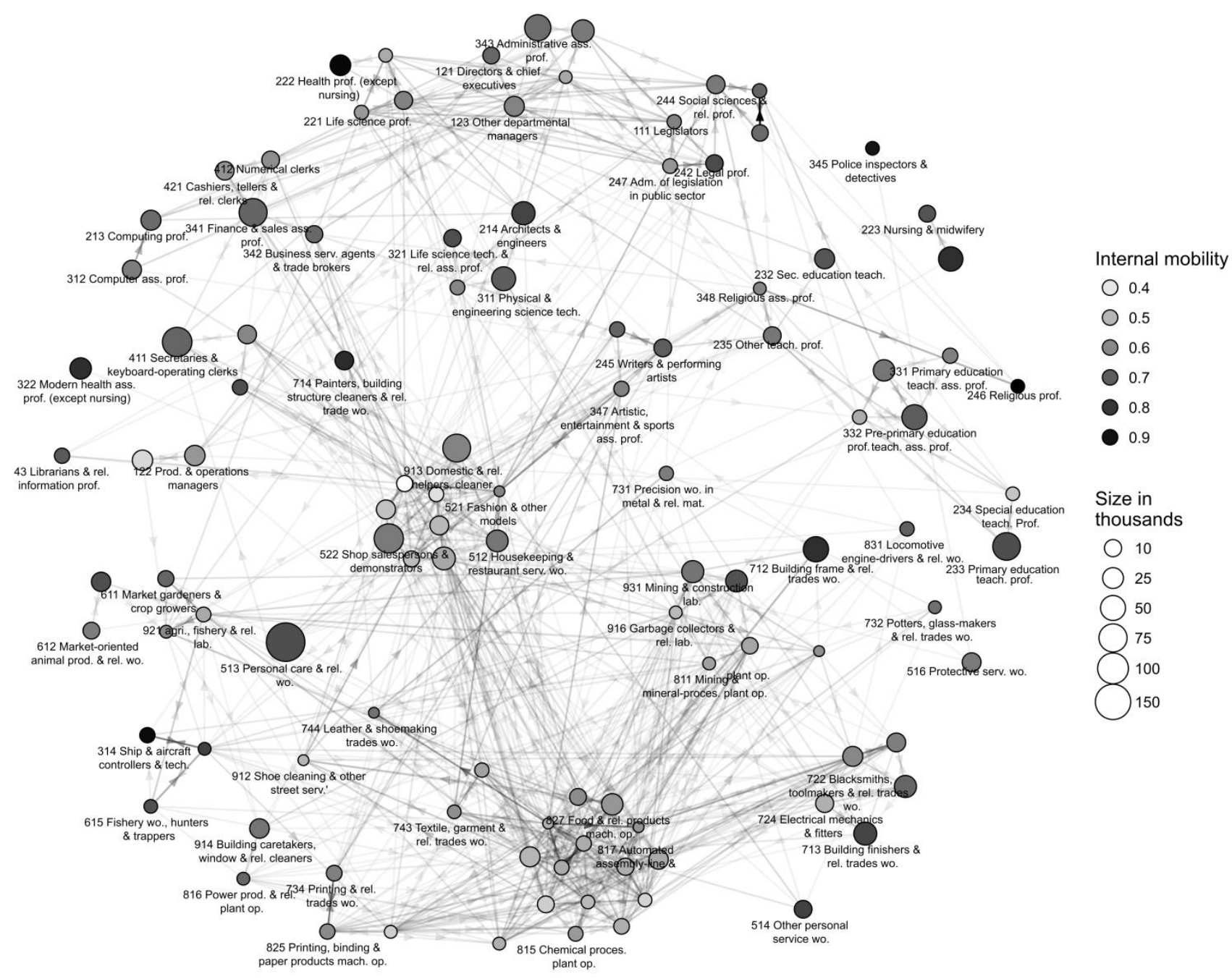

\section{The Mobility Network Clustering Algorithm (MONECA) ${ }^{2}$}

In a dense network like the one depicted in figure 1, in which almost all nodes are connected, it is difficult to make sense of the structure. In this case we look for groups of especially tightly connected nodes. The aim is to identify the cohesive and non-overlapping sub-groups of the network in order to derive the social class structure. Conventional SNA concepts such as clique and core are problematic as they produce cluster solutions that overlap. In contrast, clusters generally refer to non-overlapping cohesive sub-groups (Scott, 2000: 126ff.). Cluster analysis has the additional advantage over the sociometric concepts that it is better suited to handle weighted networks (Knoke and Yang, 2008: 80ff.). Others have used cluster analysis on distance-matrices of social mobility (e.g. Hope, 1972). The novelty of this study is the development of a cluster algorithm that clusters on the basis of weighted network ties rather than abstract distances. The principal difference is that traditional cluster analysis is based in the abstract space of the distance matrix where all categories, no matter how remote, have a distance and therefore, in principle, can be clustered. The binary logic of network ties, on the other hand, implies that unconnected categories cannot be clustered together (see Toubøl et al. 2013 for a detailed discussion of this issue). 
MONECA is designed to identify discrete clusters of interconnected nodes in a dense network. The logic of the algorithm is closely associated with the concept of the clique. The task of the algorithm is to decide to which clique to allocate the nodes that are in the overlapping area. To answer this question, the algorithm works in an agglomerative manner, considering the connections of the single pairs of nodes. The first step is to pair together the two most intensely connected nodes, which then form a cluster with the properties of a dyadic clique. In step two it proceeds to pair together the second most intensely connected pair of nodes in the same manner as in step one. And so it continues until all connections have been considered. At any subsequent step, if two nodes under consideration are already members of two different clusters, they can only be joined together if all the nodes in their respective clusters constitute a clique and, thus, can be joined together forming a new cluster. This cliquecriterion provides the stop rule for when no more single or sets of nodes should be paired together forming new clusters (for an expanded explanation of the methodology, see appendix A).

\section{The Danish intra-generational mobility structure}

The application of the above outlined approach to Danish labour market mobility data covering the period 20012007 demonstrates how a network analytical approach may provide a solution to the longstanding problem of identifying class boundaries.

The data of our study was collected by Statistics Denmark and comprises the entire Danish labour market in the period 2001-20073. This provides us with yearly information concerning the individuals' occupations (ISCO) as well as information on job shifts. With this information we can construct career sequences from 2001-2007 consisting of up to seven states in the cases of individuals employed during the entire period. We can determine whether the individuals changed their job or not as well as from, and to which occupation they moved during the transition from one state to another. In total, 11,274,435 transitions are recorded throughout the period. Of these, 1,590,834 (14.1\%) represent job shift transitions. We disaggregate the occupational coding to the threedigit level of ISCO leaving us with 109 occupational categories ${ }^{4}$ and develop a 109 x 109 occupational mobility table with 11,881 cells.

For the calculation of the RR, we weight the expected frequencies by the proportion of the total number of employees in the occupational category. To be precise, we calculate the expected frequencies of job shifts as the mean of the column and row proportions of the total number of transitions to the grand total of job-shifttransitions. Thus, the expected frequency of job shifts in a given cell depends on the total size of the row and column cell of the occupation. The reason for doing so is to avoid underestimating occupations with a large proportion of mobile employees, as well as overestimating occupations with a small proportion of mobile employees. Furthermore, despite the large amount of data, some cells in the mobility table are very sparsely populated. In order to avoid false connections due to measurement errors, cells with a frequency below the threshold of five have been erased.

The clusters are identified as described in section 4, meaning they are cliques in which all nodes are mutually connected, i.e. density $=1$. The criterion that the mobility pattern has to be mutual in order to constitute a tie is important, as we would otherwise risk joining together occupations which are linked through promotion, such as junior and senior positions in a hierarchical organisation. Thus, one-way mobility patterns do not constitute ties considered by MONECA. Forming new categories from the identified clusters, the number of categories is reduced from 109 at the original level 1 to 56 at level 2. MONECA can be used to reduce the number of categories further. We can form a new 56 x 56 directed matrix using the categories identified by MONECA at level two and perform the procedure once more. The result of what constitutes a third level in this agglomerative clustering procedure is shown in the level 3 graph of figure 2. The new clusters are marked by lines encircling existing clusters of nodes and single nodes. The new clusters are, by definition, not cliques but are, nonetheless, very dense. 
Figure 2. The five levels of the cluster analysis
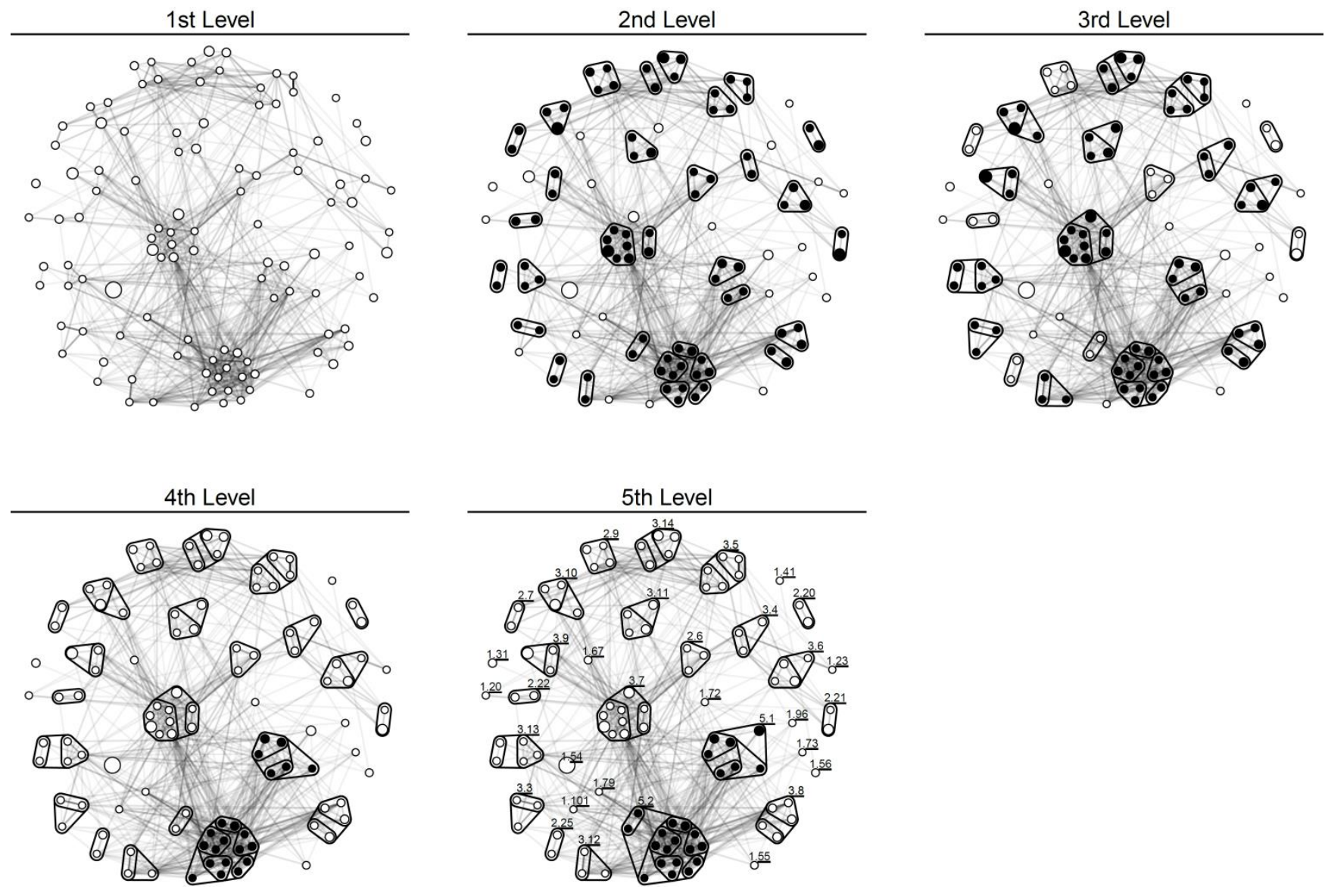

We can repeat the procedure a number of times, reducing the number of categories further (see figure 2). The amount of possible repetitions is restricted because the matrix is not hollow. As such, for each repetition which results in more aggregated categories, a larger share of the total mobility will be within-mobility located in the diagonal. This leaves less between-mobility to constitute mutual mobility patterns. Eventually, no mutual connections can be detected; hence, no more categories can be merged. Thus, MONECA has a built in stop point that is conditioned by the chosen cut point (in this case the cut point is $\mathrm{RR}=1$ ). Thus, in contrast to most agglomerative clustering algorithms, MONECA does not continue until all cases are merged into one big cluster. In this case, MONECA continues until level 5, giving us 34 categories, as can be seen from the level 5 graph of figure 2 .

\section{Results}

The result is a cluster solution of 34 occupational categories, as depicted in figure 3. Two categories are level five clusters, 12 are level three clusters, seven are level two clusters and 13 are level one clusters (for details regarding the levels of the cluster solution see appendix B). 
Figure 3. Result of cluster analysis

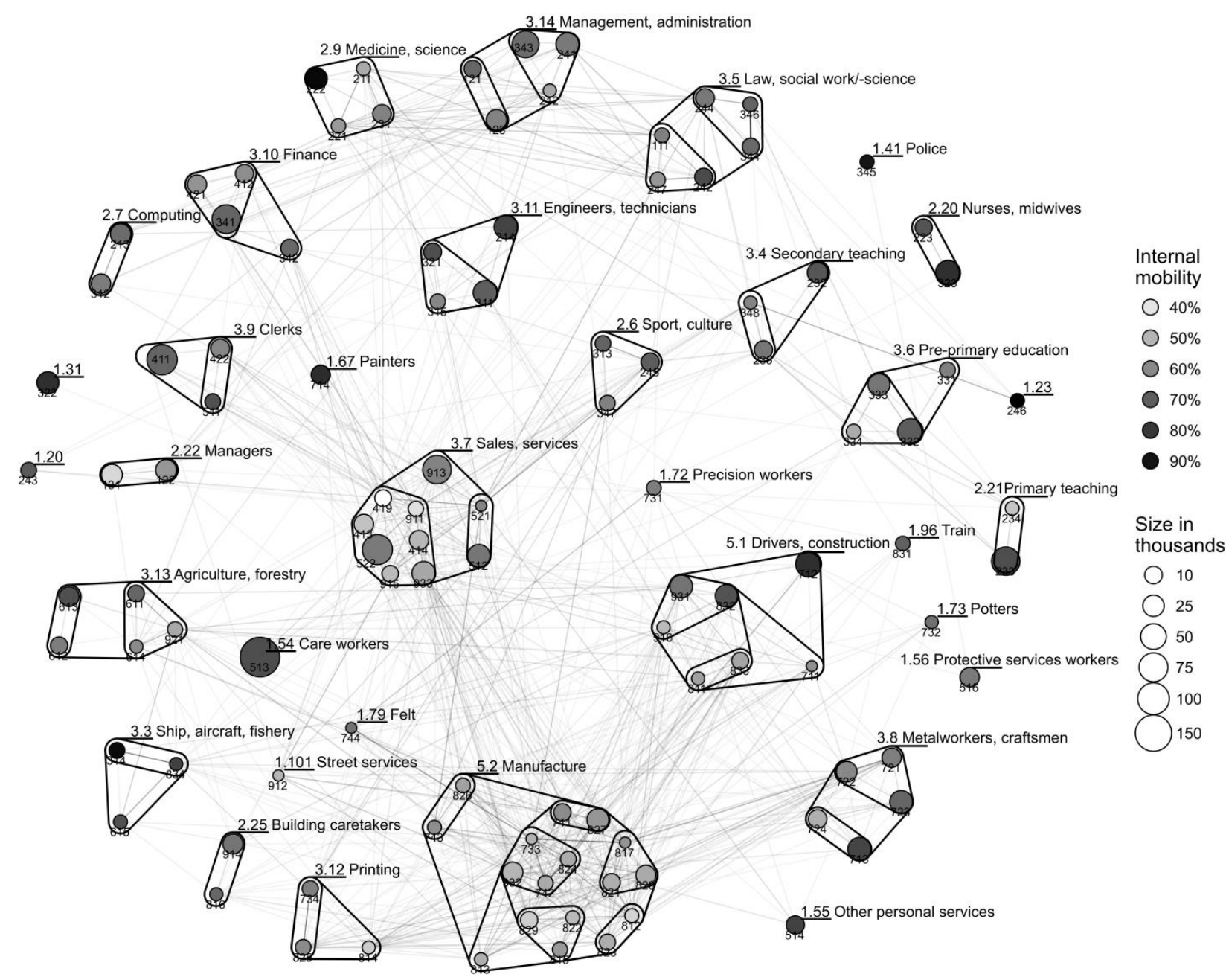

A cluster solution should always be critically inspected and assessed by the researcher. In our case this is especially important with regard to clusters formed at level three and higher. By virtue of the clustering procedure these are not cliques where movement between all occupations is easy. Hence, a critical inspection and evaluation of whether the higher level clusters are too incoherent or their boundaries are too permeable is paramount. Summary statistics of the clusters are provided in table 1. Numbers correspond to the numbers in figure 3. Titles are the product of our interpretation of what characterises the occupations of the clusters. Size refers to the share of the total number of employees at the labour market. The 10 largest categories cover $78 \%$ of the labour market. The concentration in size suggests a relatively simple class structure with a few meso-classes and several micro-classes. 
Table 1. Summary of final cluster solution produced by MONECA by size

\begin{tabular}{|c|c|c|c|c|c|}
\hline$\#$ & Title & Size & Density & Within mob. & Nodes \\
\hline 3.7 & Sales, services & 0.205 & 0.811 & 0.750 & 10 \\
\hline 1.54 & Care workers & 0.111 & $\mathrm{n} / \mathrm{a}$ & 0.740 & 1 \\
\hline 5.1 & Drivers, construction & 0.079 & 0.476 & 0.812 & 7 \\
\hline 5.2 & Manufacture & 0.066 & 0.603 & 0.673 & 17 \\
\hline 3.8 & Metalworkers, craftsmen & 0.066 & 0.850 & 0.802 & 5 \\
\hline 3.14 & Management, administration & 0.058 & 0.650 & 0.723 & 5 \\
\hline 3.9 & Clerks & 0.055 & 0.667 & 0.701 & 3 \\
\hline 3.1 & Finance & 0.054 & 0.667 & 0.713 & 4 \\
\hline 3.6 & Pre-primary education & 0.043 & 0.833 & 0.818 & 4 \\
\hline 3.11 & Engineers, technicians & 0.042 & 0.833 & 0.790 & 4 \\
\hline 2.21 & Primary teaching & 0.027 & 1.000 & 0.750 & 2 \\
\hline 2.20 & Nurses, midwives & 0.024 & 1.000 & 0.860 & 2 \\
\hline 3.5 & Law, social work/-science & 0.023 & 0.600 & 0.786 & 6 \\
\hline 2.9 & Medicine, science & 0.021 & 1.000 & 0.848 & 4 \\
\hline 2.7 & Computing & 0.020 & 1.000 & 0.770 & 2 \\
\hline 1.31 & Health associate professionals & 0.014 & $\mathrm{n} / \mathrm{a}$ & 0.820 & 1 \\
\hline 3.4 & Secondary teaching & 0.013 & 0.667 & 0.705 & 3 \\
\hline 2.22 & Managers & 0.013 & 1.000 & 0.617 & 2 \\
\hline 2.6 & Sport, culture & 0.012 & 1.000 & 0.727 & 3 \\
\hline 3.13 & Agriculture, forestry & 0.011 & 0.600 & 0.730 & 5 \\
\hline 2.25 & Building caretakers & 0.009 & 1.000 & 0.652 & 2 \\
\hline 1.67 & Painters & 0.009 & $\mathrm{n} / \mathrm{a}$ & 0.829 & 1 \\
\hline 3.3 & Ship, aircraft, fishery & 0.006 & 0.667 & 0.901 & 3 \\
\hline 1.55 & Other personal services & 0.006 & $\mathrm{n} / \mathrm{a}$ & 0.771 & 1 \\
\hline 3.12 & Printing & 0.005 & 0.667 & 0.680 & 3 \\
\hline 1.56 & Protective services workers & 0.004 & $\mathrm{n} / \mathrm{a}$ & 0.632 & 1 \\
\hline 1.20 & Archivists & 0.001 & $\mathrm{n} / \mathrm{a}$ & 0.709 & 1 \\
\hline 1.23 & Religious professionals & 0.001 & $\mathrm{n} / \mathrm{a}$ & 0.935 & 1 \\
\hline 1.72 & Precision workers & 0.001 & $\mathrm{n} / \mathrm{a}$ & 0.625 & 1 \\
\hline 1.96 & Train & 0.001 & $\mathrm{n} / \mathrm{a}$ & 0.694 & 1 \\
\hline 1.41 & Police & 0.000 & $\mathrm{n} / \mathrm{a}$ & 0.893 & 1 \\
\hline 1.73 & Potters & 0.000 & $\mathrm{n} / \mathrm{a}$ & 0.657 & 1 \\
\hline 1.79 & Pelt and leather workers & 0.000 & $\mathrm{n} / \mathrm{a}$ & 0.653 & 1 \\
\hline 1.101 & Street services & 0.000 & $\mathrm{n} / \mathrm{a}$ & 0.500 & 1 \\
\hline
\end{tabular}

Density is the share of the total number of possible edges in the cluster; the higher the density, the more coherent the cluster is, because the barriers to mobility within the cluster are low. The ideal is a clique where density equals one. All level one and two clusters are by virtue of MONECA cliques. The opposite is the case for higher level clusters, as they never have a density of one. Still, with the exception of the level five cluster 5.1 Motor vehicle drivers \& construction the density for all clusters is high $(\geq 0.6)$. Within-mobility is the share of the mobility from a given cluster going to a destination within the same cluster. This indicates the discreteness of the clusters: high within-mobility means that a cluster is relatively isolated in the social mobility structure in the sense that the chance of entering or leaving the cluster, i.e. crossing the social class boundary, is small. 
Figure 4. Reliability test results: correlations with final solution

RR cut point

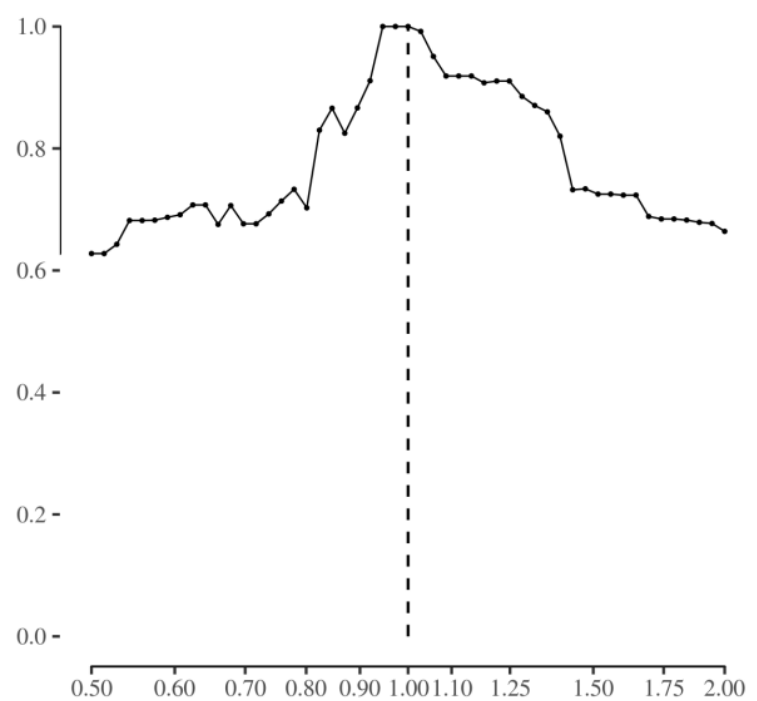

Minimum cell-frequency threshold

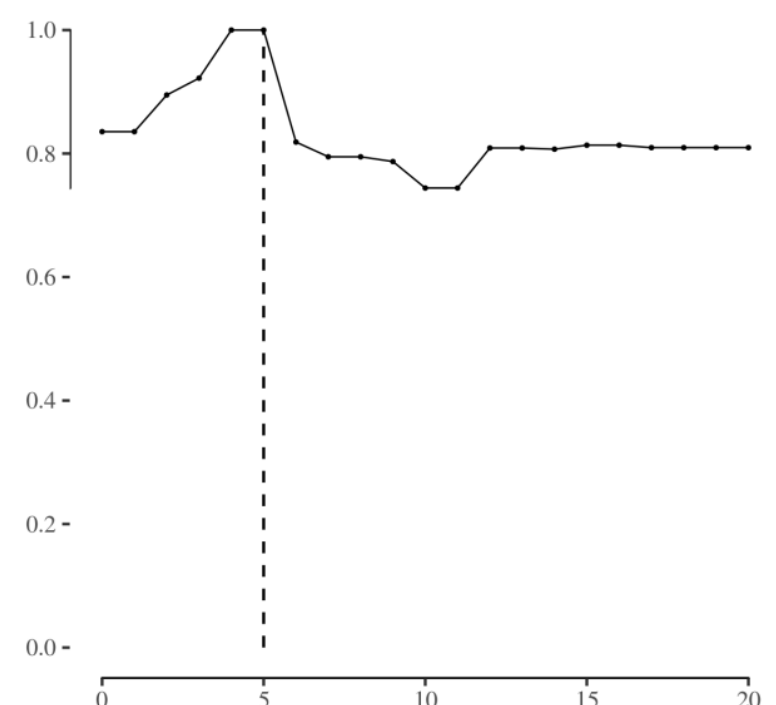

Exclusion of nodes

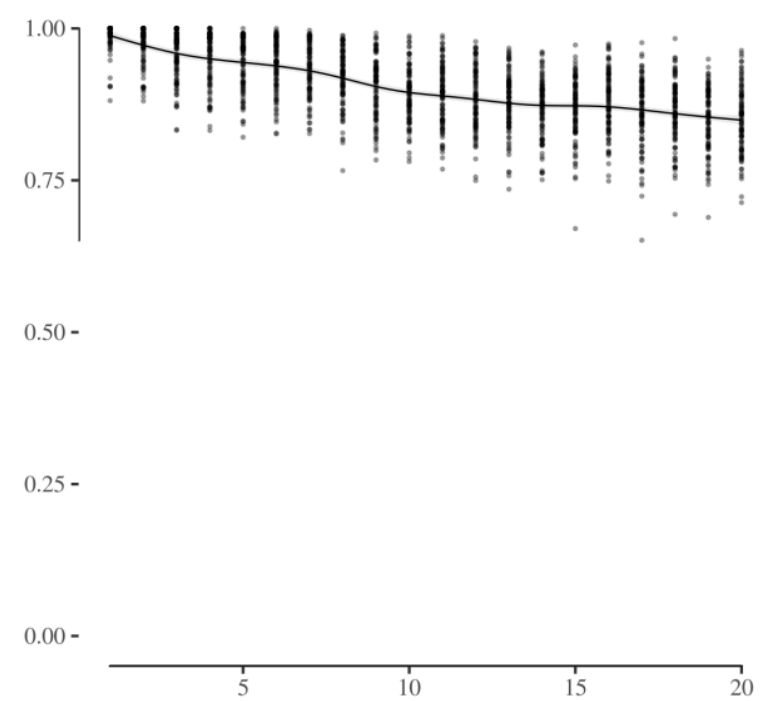


Inspecting table 1, the relatively low density of cluster 5.1 draws attention. Close inspection of the map shows that the latest addition, 712 Building frame \& related trades workers, is only connected to two of the other six occupations in the cluster, meaning that mobility from this occupation is not easy. Depending on subject matter, it might be advisable to break up the cluster and return to the level four solution, but for the sake of simplicity, and because the purpose of this paper is to demonstrate the workings of the method, we stick with MONECA's original cluster solution.

Before we turn to the discussion, we will provide the main conclusion from three reliability tests. The tests are presented in detail in appendix $\mathrm{C}$. The tests concern the RR cut point, the minimum cell-frequency threshold, and sensitivity to changes in the network. Figure 4 shows the correlation between the final cluster solution and the manipulated solutions of the three tests.

The cut point of $R R=1$ is qualified on theoretical grounds because it is equal to perfect mobility. Nonetheless, it would be critical to the reliability if small variations cause massive change to the cluster solution. This is not the case. When comparing the cluster solutions of different $R R$ cut points to the solution of an $R R=1$, the correlation never goes below 0.6 within the entire test-interval of $0.5 \leq R R \leq 2.0$, and within the $0.825 \leq R R \leq 1.3$ it is consistently higher than 0.8 . The minimum cell-frequency threshold is more critical as its determination to an extent relies on the judgement of the researcher. However, the test-results are reassuring. The correlation with the solution of a threshold of five remains around 0.8 in the entire test-interval from 0 to 20 . Finally, we test MONECA's ability to reproduce the results when erasing up to 20 randomly chosen nodes in the network, which, in turn, affects the relations between the remaining nodes. We compared the results of the reduced networks with the solution of the complete network. This was done 100 times at each level from 1-20. On average, the correlation was never lower than 0.9 and the single lowest correlation among the 2000 was 0.65 . From this we conclude that MONECA, in a fairly consistent manner, reproduces the results even when imposing rather comprehensive changes to the network.

\section{Discussion}

We begin by considering the sociological status of the categories suggested by MONECA. We then discuss the main limitations of the proposed methodology. Finally, we go beyond the dimension of mobility and consider the correspondence between the categories provided by MONECA and the factors of income, education, political behaviour and gender which represent key analytical aspects of class and stratification. In what follows, we only consider class in relation to intra-generational mobility. We do not include the class structure of intergenerational mobility, as we consider this to be a separate question.

In most studies, 34 class categories are neither analytically relevant, nor practical. As argued earlier, the 34 intra-generational social classes can be aggregated into fewer classes according to, for instance, a certain hierarchical principle, such as education or income, or other theoretical considerations. Mobility within these aggregated classes would naturally not be as likely as within the intra-generational social class categories. However, the barriers between the aggregated classes would remain in place and we are not in danger of creating a class scheme with permeable boundaries.

For theoretically derived class schemes this is not the case. As they are not derived from data on social mobility patterns they will quite likely place occupational categories with strong mutual mobility flows in separate classes, i.e. split social classes. This problem is compounded if you impose a class scheme, designed to fit a specific country in a specific historical context on another country in another historical context.

Thus, we argue that the 34 occupational clusters should be seen as intra-generational social classes which, by themselves, are of analytical interest as well as possible building blocks, from which a simpler class-map can be formed. For instance, through an empirical analysis of the categories' relation to factors such as propertyrelations, life-chances or social interaction we may find that two or more of the categories share the same 
position in the hierarchy and, thus, are segments in the same class. The result would then not violate the mobility criterion.

The method we have developed and presented in this article has two important interrelated limitations. First, the occupational classification may weaken the validity of the results if the categories do not fit the actual jobpositions in the economy, i.e. are invalid. Due to such misfits, the occupational classifications may group together dissimilar jobs or divide similar jobs into different categories. The latter scenario ought not to be a problem to the approach of this paper, as two categories with similar jobs implying a high level of intercategorical mobility would be clustered together. The former scenario, in which dissimilar jobs are grouped together in the same category, is harder to solve. In fact, we cannot be sure that this is not the case. However, the more disaggregated and detailed the baseline occupational classification, the lower the chance that dissimilar jobs are grouped in the same category.

Second, the number of observations in the data imposes limits to how disaggregated a level we can start from. A too sparsely populated mobility table lowers the validity of the subsequent analysis. The methodological approach of this paper, designed to start from a very disaggregated level in order to partially avoid the mentioned hazards inherent in any occupational classification, depends on access to large datasets on mobility. Even though few countries collect register data covering the entire population, as Denmark does, digitalization will most likely result in more such datasets becoming available to researchers in the future. Furthermore, large national survey programs provide promising sources of such large datasets on mobility by pooling the data from several rounds.

While describing the patterns of intra-generational mobility and -social class segregation in Danish society is interesting in itself, it is crucial to show that these social class categories are of importance to more than mobility. Figure 5 shows the occupations measured by gender (proportion of women), income (the crude mean of the employees' total disposable income per year after taxes, benefits and payment of interests and alimony from taxrecords in DKK. 2007 DKK/£ exchange rate $\approx 11$ ), union density (proportion of employees who were member of a trade union) and education (mean number of prescribed years of education of the highest level of education received). In table 2 , the same variables are presented by social class in descending order by income (for the exact numbers by occupation see appendix $\mathrm{D}$ and for statistics summarizing the distributions on income and education see appendix E).

Starting with income, we find that, in general, the occupations within the same social class are in the same income-range. When variation occurs, as in the case of classes 3.13 Agriculture, forestry, 3.14 Management, administration and 3.5 law, social work/-science, this variation is reflected by the subgroups of the social class.

Turning to the between variation we find large differences when we inspect the mean disposable incomes in table 2 which is ordered by income (descending). At the very top of the income scale 2.22 Managers distinguishes itself from the rest with a disposable income of DKK573,365, more than four times that of 3.7 Sales, services $(\mathrm{DKK} 134,150)$ at the bottom of the table and the income scale. This exclusive management group only makes up $1.3 \%$ of the labour market ${ }^{5}$. Next follows a group of nine high income social classes, in descending order from 3.3 Ship, aircraft, fishery (DKK324,543) to 3.1 Finance (DKK256,265). They make up almost a quarter $(23.7 \%)$ of the labour market,. Then follows a large group going from 1.96 Train (DKK231,657) to 1.101 Street services (DKK178,708). This group constitutes $42.8 \%$ of the labour market. Finally, we have a group of four relatively low income social classes going from Potters (DKK170,028) to 3.7 Sales, services (DKK134,150). Together they make up almost a third of the labour market, $32.2 \%$.

Following these observations, a classification based on a hierarchy of income suggests four aggregate classes: 1) A tiny elite class consisting of top level management, 2) an upper middle class consisting of lower level management, academics, administrators, specialists and the financial sector, 3) a large and heterogeneous middle class consisting of both blue and white collar workers, and 4) a large lower class consisting of service workers. 


\section{Mapping the social class structure}

Figure 5. Occupations by income, education, union density and gender distribution in 2007

Proportion of women

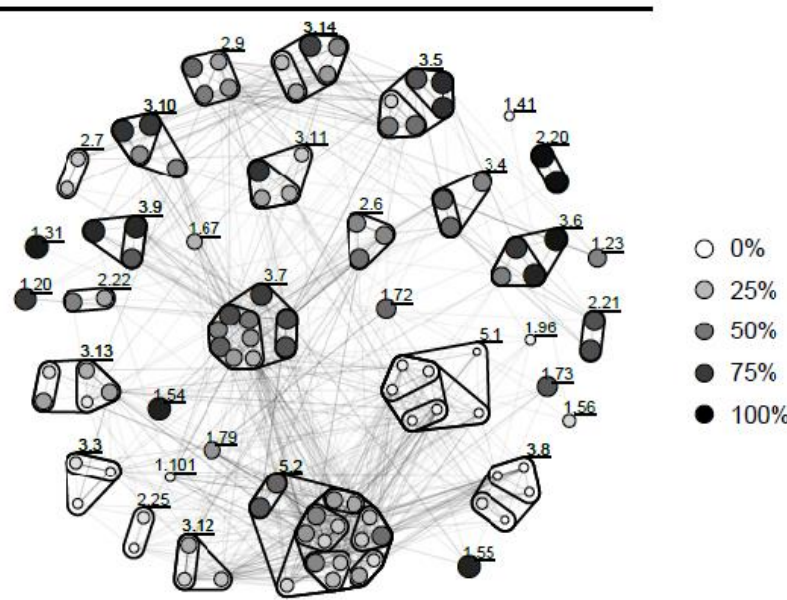

Union density

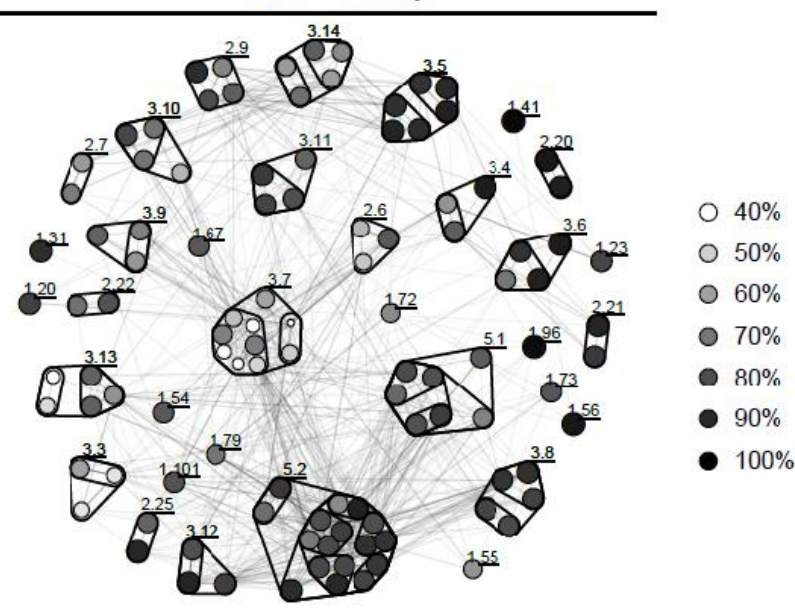

Income in thousands DKK

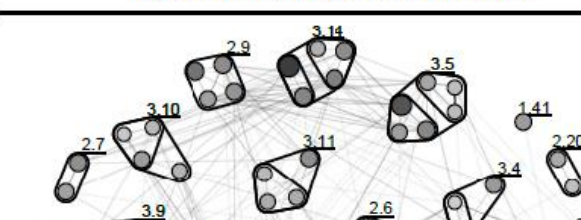

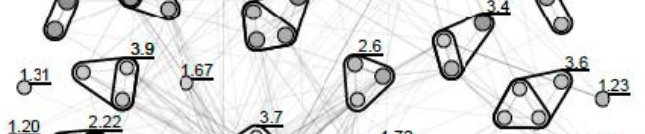
3.13

300 - 500

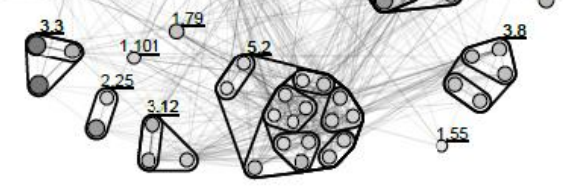
Length of education in years

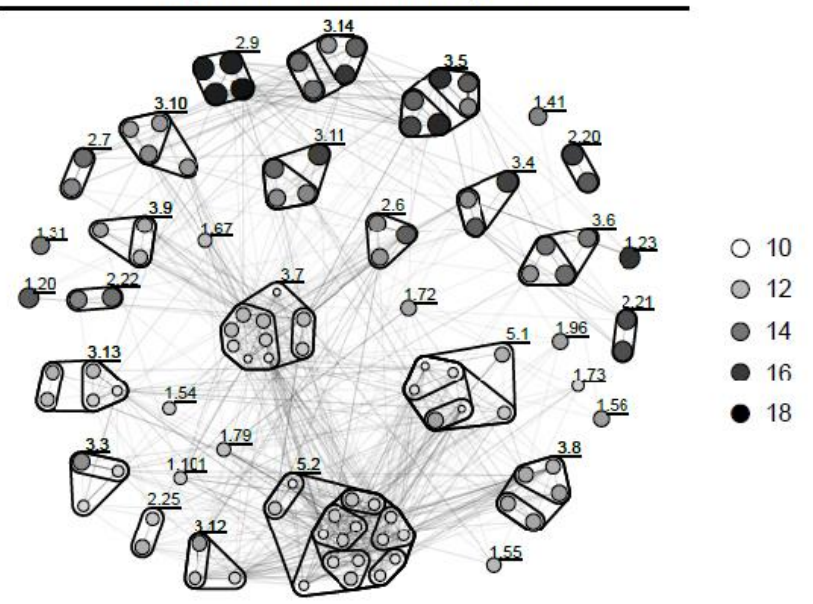


Mapping the social class structure

Table 2. Clusters by income, education, union density and gender distribution in 2007

\begin{tabular}{|c|c|c|c|c|}
\hline$\#$ & Disp. Income (DKK) & Education, years & Union density & Share of women \\
\hline 2.22 & 573,365 & 14.1 & $77.6 \%$ & $33.3 \%$ \\
\hline 3.3 & 324,543 & $12.8^{*}$ & $57.3 \%$ & $9.4 \%$ \\
\hline 2.9 & 319,998 & 17.2 & $82.6 \%$ & $47.9 \%$ \\
\hline 2.7 & 283,378 & 14.0 & $64.5 \%$ & $20.7 \%$ \\
\hline 1.41 & 274,551 & 13.6 & $98.6 \%$ & $2.9 \%$ \\
\hline 3.11 & 263,466 & 14.5 & $78.5 \%$ & $31.3 \%$ \\
\hline 3.14 & 260,838 & 13.6 & $72.5 \%$ & $62.3 \%$ \\
\hline 3.5 & 259,903 & 15.7 & $89.2 \%$ & $64.6 \%$ \\
\hline 3.4 & 257,314 & 15.3 & $86.0 \%$ & $48.9 \%$ \\
\hline 3.1 & 256,265 & 13.2 & $70.2 \%$ & $48.3 \%$ \\
\hline 1.96 & 231,657 & 12.7 & $97.9 \%$ & $4.5 \%$ \\
\hline 3.13 & 231,378 & 11.9 & $59.5 \%$ & $23.1 \%$ \\
\hline 2.6 & 229,191 & 14.1 & $66.9 \%$ & $45.6 \%$ \\
\hline 1.23 & 224,456 & 16.3 & $82.2 \%$ & $44.7 \%$ \\
\hline 1.56 & 222,799 & 12.7 & $95.2 \%$ & $13.6 \%$ \\
\hline 3.12 & 219,583 & 12.0 & $85.9 \%$ & $21.5 \%$ \\
\hline 2.20 & 218,122 & 15.1 & $93.2 \%$ & $95.4 \%$ \\
\hline 2.21 & 216,611 & 15.3 & $85.6 \%$ & $66.5 \%$ \\
\hline 1.20 & 215,744 & 14.9 & $83.6 \%$ & $75.1 \%$ \\
\hline 1.79 & 206,694 & 11.8 & $70.5 \%$ & $38.8 \%$ \\
\hline 3.8 & 203,340 & 12.5 & $83.8 \%$ & $2.6 \%$ \\
\hline 5.1 & 195,615 & 11.3 & $78.7 \%$ & $3.7 \%$ \\
\hline 3.9 & 192,325 & 12.6 & $72.6 \%$ & $82.7 \%$ \\
\hline 1.72 & 192,225 & 12.5 & $65.1 \%$ & $55.4 \%$ \\
\hline 3.6 & 191,953 & 14.2 & $89.6 \%$ & $81.5 \%$ \\
\hline 1.31 & 191,830 & 13.8 & $88.7 \%$ & $91.3 \%$ \\
\hline 2.25 & 189,132 & 11.6 & $75.5 \%$ & $10.2 \%$ \\
\hline 1.67 & 181,745 & 11.8 & $77.7 \%$ & $26.9 \%$ \\
\hline 5.2 & 181,414 & 11.1 & $82.3 \%$ & $35.3 \%$ \\
\hline 1.101 & 178,708 & 11.6 & $78.7 \%$ & $4.3 \%$ \\
\hline 1.73 & 170,028 & 11.3 & $77.7 \%$ & $63.6 \%$ \\
\hline 1.54 & 164,446 & 11.6 & $77.0 \%$ & $87.8 \%$ \\
\hline 1.55 & 145,392 & 12.0 & $63.3 \%$ & $86.3 \%$ \\
\hline 3.7 & 134,150 & 11.1 & $50.7 \%$ & $55.9 \%$ \\
\hline Total & 201,561 & 12.7 & $74.1 \%$ & $51.9 \%$ \\
\hline
\end{tabular}

* The very low mean years of education is due to aircraft pilots and air traffic controllers being registered with unrealistically short educations for reasons unknown (Albæk and Thomsen, 2011: 28).

Such a simple four-group hierarchy becomes problematic if we take education into consideration. The correspondence between level of income and education is far from perfect. For instance, the members of group 2.22 Managers with a mean income of DKK573,365 have a mean of 14.2 years of education. Members of 3.6 Preprimary education who also have a mean of 14.2 years of education, on the other hand, have an income of less than 
half that amount (DKK191,953). At the bottom of table 2, people in low income category of 3.7 Sales, services unsurprisingly also have relatively short educations (DKK134,150/11.1). However, surprisingly, people in the groups 5.1 Drivers, construction and 5.2 Manufacture, who have equivalent levels of education, have a much higher income (respectively DKK195,615/11.3 and DKK181,414/11.1). These discrepancies between income and education indicate that the individuals' income is not only a product of human capital possession but also depends on their (social) class membership.

The relationship between class and political action is central to the discussion of the relevance of class. Usually, this has been discussed in terms of political partisanship. We take a slightly different approach and look at the degree of unionization. Even though unions are not political parties, they are political organizations and in Denmark, unions have historically been strongly associated with the political left (Toubøl and Jensen 2014).

In international comparison, the overall union density in Denmark is, at $74.1 \%$, very high. Despite the general high level of unionization, there are considerable variations in union density among occupations. This may indicate that unionization is one of the factors influencing income distribution. An example of this is the contrast between 3.7 Sales, services, which has the lowest union density of all social classes $(50.7 \%$,) and 5.1 Drivers, construction and 5.2 Manufacture with union densities well above average (78.7\% and $82.3 \%$ respectively). A possible explanation of why the income level relative to educational level is so much higher in 5.1 and 5.2 compared to 3.7 is that unions are much stronger in 5.1 and 5.2. However, unions do not explain the low income level relative to the level of education of 3.6 Pre-primary education, 2.20 Nurses, midwifes and 2.21 Primary teaching. These categories have a high union density, well above average, but they still have low incomes relative to the level of education. We suggest that the explanation may be related to the extra-class factor of gender.

Gender is related to stratification theory but it is usually treated as a dimension distinct from class. However, the growing awareness of the intersectional nature of inequality (e.g. Walby et al., 2012) calls for the combination of class and gender, among other factors. In figure 5 and table 2 we register great variation in the proportion of women among occupations. The intra-generational social class categories reflect these variations. The lowincome category 3.7 Sales, services has a relatively high proportion of women (55.9\%) compared to 5.2 Manufacture $(35.3 \%)$ and especially 5.1 Drivers, construction $(3.7 \%)$. However, we find the highest proportion of women among all social classes in 2.20 Nurses, midwifes (95.4\%), while also 3.6 Pre-primary education (81.5\%) and 2.21 Primary teaching $(66.5 \%)$ have proportions of women well above the overall average of $51.9 \%$. These correlations indicate a negative relationship between income and the proportion of women in a social class.

\section{Conclusion}

The preceding discussion argues that employing descriptive methods like MONECA makes it possible to investigate the multidimensional nature of class structuration. Hence, the above outlined method and approach call for a more nuanced theoretical approach to class. The results also underline the need to focus on society and context specific explorations of class structure, rather than universal class schemes. The mapping of the Danish intra-generational social class structure 2001-2007 in this article suggests that things are much more complex than what any single universal class scheme and theory is able to grasp. Furthermore, given this complexity, it is only reasonable to expect significant variation between different societies.

The above outlined methodological approach provides two innovations directed to the task of society and context specific analysis of class structure. First, the conceptualization of the mobility table as a network enables us to depict the social mobility structure in a transparent and intuitively meaningful way, which corresponds with the basic imagery of social class and social mobility theory. Based on a simple probability model of randomness, mobility barriers become visible. Furthermore, we can distinguish between the direction and the relative intensity of the flow and take the differences in proportion of mobile workforce and the proportion of internal mobility into account.

Second, MONECA enables us to identify discrete clusters of occupations between which mobility is easy and typical, and it provides a methodological means to give substance to Weber's rudimentary definition of social 
class. The clusters identified provide the basic intra-generational social class categories. These should be perceived as the result of an exploratory and descriptive analysis, mapping the social class categories of the intragenerational social mobility structure. However, subsequent explanatory analysis should have these categories as a basic starting point. The social classes may be aggregated into fewer and larger classes if an extended definition of class is employed. However, a social class category should never be split into different categories within a class scheme as the boundaries of the new class categories would be permeable. The validity of such a class scheme would not meet the mobility criterion.

As indicated by the preliminary and strictly descriptive analysis of the prominent variables income, education, gender and political action, the intra-generational social class map identified, reflects important factors of differentiation. Through the precise identification of boundaries, the social class map derived in the manner outlined above may very well provide a better starting point for the investigation of the factors driving class formation than the hitherto dominant theory-driven approaches.

Going beyond the question of class and social mobility, MONECA is useful for the analysis of any dense, weighted network from which it is meaningful to extract discrete categories based on a principle of connectivity. Thus, the outlined exploratory and data driven approach to categorization may prove very useful in providing the fundamental categories for research into other questions than social mobility. 


\section{Acknowledgements}

We are grateful to Thomas P. Boje, Peter Gundelach, Bue Rübner Hansen, Christian Lyhne Ibsen, Carsten Strøby Jensen, and Jens-Peter Thomsen as well as the anonymous reviewers for indispensable comments and suggestions.

\section{Notes}

1. The data-package MONECA written in R is freely available from https://github.com/antongrau/moneca. It includes tools for transforming a table of associations into a weighted network and subsequent analysis with the MONECA algorithm including outputs summarising the process as well as providing descriptive measures useful for assessing the qualities of the clusters, some of which has been discussed in this article and provided in the appendices.

2. The argument of this section have previously been presented in a modified version at the XXXIII Sunbelt Social Networks Conference (Toubøl et al., 2013).

3. This definition excludes persons who are not active on the labour market. The most notable excluded groups are children, unemployed, persons on leave including sick leave or parental leave, senior citizens and affluent persons living from capital returns.

4. The Military has been excluded because this occupational category covers a very diverse range of jobs and qualifications, which makes it analytically troublesome. Danish military is relatively small and the exclusion is not as problematic as in the cases of countries with large militaries.

5. However, even within this group, an even more exclusive income group exists, which is revealed by comparing the mean of DKK573,365 to the median of DKK264,893 (See appendix E). 


\section{References}

Albæk K and Thomsen LB (2011) Er Kvindefag lavtlonsfag? En analyse af sammenbangen mellem lon og andelen af kvinder $i$ enkelte arbejdsfunktioner. SFI-rapporter, København: SFI--Det nationale forskningscenter for velfærd.

Andersen PL and Hansen MN (2012) Class and Cultural Capital-The Case of Class Inequality in Educational Performance. European Sociological Review 28(5): 607-621.

Blau PM and Duncan OD (1967) The American Occupational Structure. New York: John Wiley \& Sons.

Bourdieu P (1984) Distinction, a social critique of the judgement of taste. Routledge \& Kegan Paul.

Bourdieu P (1987) What Makes a Social Class? On The Theoretical and Practical Existence Of Groups. Berkeley Journal of Sociology 32: 1-17.

Breiger RL (1981) The Social Class Structure of Occupational Mobility. American Journal of Sociology 87(3): 578611.

Clogg CC and Goodman LA (1984) Latent Structure Analysis of a Set of Multidimensional Contingency Tables. Journal of the American Statistical Association 79(388): 762-771.

Duncan OD (1961) A Socioeconomic Index for all Occupations. In: Reiss AJ (ed.), Occupations and social status, New York: Free Press of Glencoe, pp. 109-138.

Erikson R and Goldthorpe JH (1993) The constant flux, a study of class mobility in industrial societies. Clarendon.

Erikson R, Goldthorpe JH and Hällsten M (2012) No way back up from ratcheting down? A critique of the "microclass" approach to the analysis of social mobility. Acta Sociologica 55(3): 211-229.

Giddens A (1973) The class structure of the advanced societies. London: Hutchinson.

Goldthorpe JH (2007) On sociology. 2. ed. Stanford University Press.

Goodman LA (1981) Criteria for Determining Whether Certain Categories in a Cross-Classification Table Should Be Combined, with Special Reference to Occupational Categories in an Occupational Mobility Table. American Journal of Sociology 87(3): 612-650.

Griffiths D and Lambert P (2012) Dimensions and Boundaries: Comparative Analysis of Occupational Structures Using Social Network and Social Interaction Distance Analysis. Sociological Research Online 17(2): 5.

Grusky DB and Weeden KA (2002) Class Analysis and the Heavy Weight of Convention. Acta Sociologica 45(3): 229-236.

Hope K (1972) Quantifying Constraints on Social Mobility: The Latent Hierarchies of a Contingency Table. In: Hope K (ed.), The Analysis of social mobility; methods and approaches, Oxford studies in social mobility. Working papers, Oxford: Clarendon Press, pp. 121-190.

Jonsson JO, Grusky DB, Carlo MD, et al. (2009) Microclass Mobility: Social Reproduction in Four Countries. American Journal of Sociology 114(4): 977-1036.

Klatzky SR and Hodge RW (1971) A Canonical Correlation Analysis of Occupational Mobility. Journal of the American Statistical Association 66(333): 16-22.

Knoke D and Yang S (2008) Social Network, Analysis. Thousand Oaks: SAGE Publications, Inc. 
Levine JH (1972) A Two-Parameter Model of Interaction in Father-Son Status Mobility. Bebavioral Science 17(5): 455-465.

MacDonald K (1972) MDSCAL and Distances Between Socio-Economic Groups. In: Hope K (ed.), The Analysis of social mobility; methods and approaches, Oxford studies in social mobility. Working papers, Oxford: Clarendon Press, pp. 211-234.

Marx K and Engels F (2008) The communist manifesto. London: Pluto Press.

Pakulski J (2005) Foundations of a post-class analysis. In: Wright EO (ed.), Approaches to class analysis, Cambridge, UK; New York: Cambridge University Press, pp. 152-179.

Prandy K and Lambert P (2003) Marriage, Social Distance and the Social Space: An Alternative Derivation and Validation of the Cambridge Scale. Sociology 37(3): 397-411.

Savage M, Devine F, Cunningham N, et al. (2013) A New Model of Social Class? Findings from the BBC's Great British Class Survey Experiment. Sociology 47(2): 219-250.

Savage M, Devine F, Cunningham N, et al. (2015) On Social Class, Anno 2014. Sociology 49(6): 1011-1030.

Scott J (2000) Social Network. Analysis. A Handbook. London: SAGE.

Stewart A, Prandy K and Blackburn RM (1980) Social stratification and occupations. New York: Holmes \& Meier.

Treiman DJ (1977) Occupational prestige in comparative perspective. Quantitative studies in social relations, New York: Academic Press.

Toubøl J, Larsen AG and Jensen CS (2013) A network analytical approach to the study of labour market mobility. Paper presented at XXXIII Sunbelt Social Networks Conference of the International Network for Social Network Analysis (INSNA), Hamburg, Germany.

Toubøl J and Jensen CS (2014) Why do people join trade unions? The impact of workplace union density on union recruitment. Transfer: European Review of Labour and Research 20(1): 135-154.

Wacquant L (2013) Symbolic Power and Group-making: On Pierre Bourdieu's Reframing of Class. Journal of Classical Sociology 13(2): 274-291.

Walby S, Armstrong J and Strid S (2012) Intersectionality: Multiple Inequalities in Social Theory. Sociology 46(2): 224-240.

Weber M (1978) Economy and society: an outline of interpretive sociology. Berkeley: University of California Press.

Weeden KA and Grusky DB (2005) The Case for a New Class Map. American Journal of Sociology 111(1): 141-212.

Weeden KA and Grusky DB (2012) The Three Worlds of Inequality. American Journal of Sociology 117(6): 17231785.

Wright EO (1989) A General Framework for the Analysis of Class Structure. In: Wright EO (ed.), The Debate on Classes, London; New York: Verso.

Wright EO (2005) Foundations of a neo-Marxist class analysis. In: Wright EO (ed.), Approaches to class analysis, Cambridge, UK; New York: Cambridge University Press, pp. 4-30. 
Mapping the social class structure

\section{Author biographies}

Jonas Toubøl is a PhD Fellow at Department of Sociology, University of Copenhagen. His research interests are in political sociology and social stratification, especially social movements, class and labour market segmentation.

Anton Grau Larsen is Assistant Professor at Copenhagen Business School, Department of Business and Politics. His research interest are in elites, power, field analysis, class, and the methodologies of social network analysis and correspondence analysis. 


\section{Appendix A. Explaining and exemplifying The Mobility Network Clustering Algorithm}

The arguments and figures in this appendix is a modified version of sections in Toubøl et al. (2013).

The MONECA algorithm is designed to identify discrete clusters of interconnected nodes in dense networks, as the one presented in figure A1. The figure depicts a graph of a rather dense weighted network as well as its adjacency table. The maximal cliques of the graph are $|\mathrm{ABC}|$ and $|\mathrm{BCD}|$, which overlap each other in the case of 2 out of 3 nodes. In such a case, seeking to identify discrete clusters by a simple analysis of the cliques is a futile endeavour. MONECA offers a way to make sense of the discrete clustering structure of the network. In the following, we start by explaining the logic of MONECA followed by an example.

Figure A1: Exemplifying the MONECA algorithm

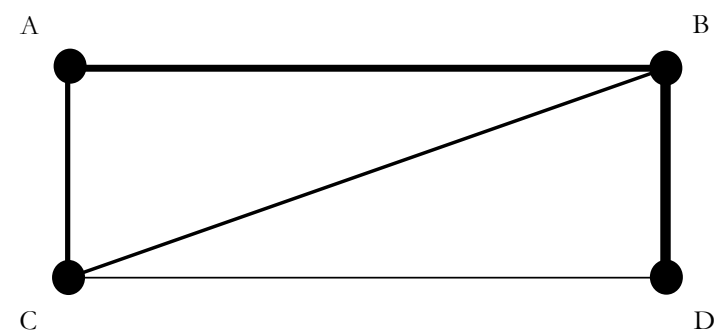

\begin{tabular}{|c|c|c|c|c|}
\hline & A & B & C & D \\
\hline A & & & & \\
\hline B & 4 & & & \\
\hline C & 3 & 2 & & \\
\hline D & 0 & 6 & 1 & \\
\hline
\end{tabular}

Note: This figure has prior been presented at the XXXIII Sunbelt Social Networks Conference (Toubøl et al., 2013).

The logic of the algorithm is closely associated with the concept of the clique. The task of the algorithm is to determine to which clique to allocate the nodes that are in the overlapping areas of two or more cliques, as is the case of node B and C in figure A1. The network of figure A1 is weighted. The weights express the intensity of the relations of the nodes. This information enables the algorithm to decide which clique nodes $\mathrm{B}$ and $\mathrm{C}$ should belong to. Thus, in order to be able to produce a solution with MONECA, a network has to be weighted.

The algorithm is agglomerative, starting from the most disaggregated level, considering the connections of the single pairs of nodes. First step is to pair together the two most intensely connected nodes which then form a cluster. Subsequently, the connection between these two nodes is not considered. In step two MONECA proceeds to pair together the two nodes, which, among those remaining, are most intensely connected, in the same manner as in step one. And so it continues until all connections have been considered.

If one or both of the two most intensely connected nodes are already members of different clusters, they can only be joined together if all the nodes in the respective clusters are joined together, forming a new big cluster. However, a set of nodes can only be considered a cluster if they also form a clique. Therefore, in the case of pairing together two clusters, or adding a single node to an existing cluster, this is only possible if all the nodes under consideration form a clique. This criterion provides the stop rule for when no more single or sets of nodes should be paired together to form new clusters. Otherwise, the cluster solution would simply be the components of the network.

An example of how the algorithm works should clarify the procedure: In the case of figure A1, B and D are the most intensely connected nodes which can be seen from the width of the ties representing the intensity of the relation. Then, $\mathrm{B}$ and $\mathrm{D}$ are paired together, to form a preliminary cluster, $|\mathrm{BD}|$. The second most intense connection is that of $\mathrm{A}$ and $\mathrm{B}$. However, $|\mathrm{BD}|$ are already a cluster so MONECA asks whether A can be paired with both $\mathrm{B}$ and $\mathrm{D}$, forming the cluster of $|\mathrm{ABD}|$. In order to settle this question, MONECA must determine whether $|\mathrm{ABD}|$ constitutes a clique. In this case $|\mathrm{ABD}|$ is not a clique, because nodes $\mathrm{A}$ and $\mathrm{D}$ are not connected. Thus, nodes $\mathrm{A}$ and $\mathrm{B}$ cannot be paired. MONECA then goes on to consider the third strongest 
connection, which is $\mathrm{A}$ and $\mathrm{C}$. Neither $\mathrm{A}$ or $\mathrm{C}$ are members of a preliminary cluster, and they can therefore be paired without further ado. We now have two clusters: $|\mathrm{BD}|$ and $|\mathrm{AC}|$. The fourth strongest connection is BC. However, $\mathrm{B}$ has already been paired with $\mathrm{D}$, and $\mathrm{C}$ has been paired with A. MONECA asks whether $|\mathrm{ABCD}|$ constitutes a clique. The answer is no, because $\mathrm{A}$ and $\mathrm{D}$ are not connected. Hence, $|\mathrm{AC}|$ and $|\mathrm{BD}|$ cannot be paired. The same is the case with regard to the fifth connection, $|\mathrm{CD}|$. As result, the cluster solution produced by the algorithm is $|\mathrm{AC}|$ and $|\mathrm{BD}|$, and none of the maximal cliques, $|\mathrm{ABC}|,|\mathrm{BCD}|$. 
Mapping the social class structure

Appendix B. Cluster structure

\begin{tabular}{|c|c|c|c|c|c|c|c|c|c|c|c|c|c|c|c|c|c|c|c|c|c|}
\hline \multirow[b]{2}{*}{ Occupation } & \multirow[b]{2}{*}{$\begin{array}{l}\text { Final } \\
\text { Cluster }\end{array}$} & \multicolumn{4}{|c|}{ Level 1} & \multicolumn{4}{|c|}{ Level 2} & \multicolumn{4}{|c|}{ Level 3} & \multicolumn{4}{|c|}{ Level 4} & \multicolumn{4}{|c|}{ Level 5} \\
\hline & & Cluster & $\begin{array}{l}\text { Witbin } \\
\text { mob. }\end{array}$ & Density & Size & Cluster & $\begin{array}{c}\text { Within } \\
\text { mob. }\end{array}$ & Density & Size & Cluster & $\begin{array}{c}\text { Within } \\
\text { mob. }\end{array}$ & Density & Size & Cluster & $\begin{array}{c}\text { Within } \\
\text { mob. }\end{array}$ & Density & Size & Cluster & $\begin{array}{c}\text { Witbin } \\
\text { mob. }\end{array}$ & Density & Size \\
\hline 832 Motor vehicle drivers & 5.10 & 97 & 0.728 & & 0.016 & 18 & 0.707 & 1.000 & 0.034 & 1 & 0.714 & 0.750 & 0.039 & 1 & 0.715 & 0.567 & 0.039 & 1 & 0.812 & 0.476 & 0.066 \\
\hline 916 Garbage collectors \& rel. lab. & 5.10 & 105 & 0.491 & & 0.001 & 18 & 0.707 & 1.000 & 0.034 & 1 & 0.714 & 0.750 & 0.039 & 1 & 0.715 & 0.567 & 0.039 & 1 & 0.812 & 0.476 & 0.066 \\
\hline 931 Mining \& construction lab. & 5.10 & 107 & 0.647 & - & 0.017 & 18 & 0.707 & 1.000 & 0.034 & 1 & 0.714 & 0.750 & 0.039 & 1 & 0.715 & 0.567 & 0.039 & 1 & 0.812 & 0.476 & 0.066 \\
\hline 811 Mining \& mineral-proces. & 5.10 & 80 & 0.545 & - & 0.000 & 24 & 0.539 & 1.000 & 0.005 & 1 & 0.714 & 0.750 & 0.039 & 1 & 0.715 & 0.567 & 0.039 & 1 & 0.812 & 0.476 & 0.066 \\
\hline 833 agri. \& other mobile plant op. & 5.10 & 98 & 0.535 & - & 0.004 & 24 & 0.539 & 1.000 & 0.005 & 1 & 0.714 & 0.750 & 0.039 & 1 & 0.715 & 0.567 & 0.039 & 1 & 0.812 & 0.476 & 0.066 \\
\hline 711 Miners, \& stonecutters & 5.10 & 64 & 0.583 & - & 0.000 & - & - & - & - & - & - & - & - & 1 & 0.715 & 0.567 & 0.039 & 1 & 0.812 & 0.476 & 0.066 \\
\hline $\begin{array}{l}712 \text { Building frame } \& \text { rel. trades } \\
\text { wo. }\end{array}$ & 5.10 & 65 & 0.820 & - & 0.028 & - & - & - & - & - & - & - & - & - & - & - & - & 1 & 0.812 & 0.476 & 0.066 \\
\hline 733 Handicraft wo. in wood, textile & 5.20 & 74 & 0.511 & - & 0.000 & 2 & 0.544 & 1.000 & 0.016 & 2 & 0.668 & 0.698 & 0.063 & 2 & 0.669 & 0.648 & 0.064 & 2 & 0.673 & 0.603 & 0.066 \\
\hline $\begin{array}{l}742 \text { Wood treaters \& rel. trades } \\
\text { wo. }\end{array}$ & 5.20 & 77 & 0.525 & - & 0.002 & 2 & 0.544 & 1.000 & 0.016 & 2 & 0.668 & 0.698 & 0.063 & 2 & 0.669 & 0.648 & 0.064 & 2 & 0.673 & 0.603 & 0.066 \\
\hline 824 Wood products mach. op. & 5.20 & 90 & 0.521 & - & 0.002 & 2 & 0.544 & 1.000 & 0.016 & 2 & 0.668 & 0.698 & 0.063 & 2 & 0.669 & 0.648 & 0.064 & 2 & 0.673 & 0.603 & 0.066 \\
\hline 932 Manufacturing lab. & 5.20 & 108 & 0.500 & - & 0.011 & 2 & 0.544 & 1.000 & 0.016 & 2 & 0.668 & 0.698 & 0.063 & 2 & 0.669 & 0.648 & 0.064 & 2 & 0.673 & 0.603 & 0.066 \\
\hline 741 Food proces. \& rel. trades wo. & 5.20 & 76 & 0.592 & - & 0.005 & 10 & 0.649 & 1.000 & 0.020 & 2 & 0.668 & 0.698 & 0.063 & 2 & 0.669 & 0.648 & 0.064 & 2 & 0.673 & 0.603 & 0.066 \\
\hline $\begin{array}{l}827 \text { Food \& rel. products mach. } \\
\text { op. }\end{array}$ & 5.20 & 93 & 0.570 & & 0.015 & 10 & 0.649 & 1.000 & 0.020 & 2 & 0.668 & 0.698 & 0.063 & 2 & 0.669 & 0.648 & 0.064 & 2 & 0.673 & 0.603 & 0.066 \\
\hline 817 Automated assembly-line & 5.20 & 86 & 0.575 & - & 0.000 & 13 & 0.544 & 1.000 & 0.015 & 2 & 0.668 & 0.698 & 0.063 & 2 & 0.669 & 0.648 & 0.064 & 2 & 0.673 & 0.603 & 0.066 \\
\hline 821 Metal \& mineral prod. & 5.20 & 87 & 0.515 & - & 0.006 & 13 & 0.544 & 1.000 & 0.015 & 2 & 0.668 & 0.698 & 0.063 & 2 & 0.669 & 0.648 & 0.064 & 2 & 0.673 & 0.603 & 0.066 \\
\hline 828 Assemblers & 5.20 & 94 & 0.525 & - & 0.010 & 13 & 0.544 & 1.000 & 0.015 & 2 & 0.668 & 0.698 & 0.063 & 2 & 0.669 & 0.648 & 0.064 & 2 & 0.673 & 0.603 & 0.066 \\
\hline 815 Chemical process. plant op. & 5.20 & 84 & 0.560 & - & 0.002 & 15 & 0.492 & 1.000 & 0.008 & 2 & 0.668 & 0.698 & 0.063 & 2 & 0.669 & 0.648 & 0.064 & 2 & 0.673 & 0.603 & 0.066 \\
\hline 822 Chemical products mach. op. & 5.20 & 88 & 0.491 & - & 0.001 & 15 & 0.492 & 1.000 & 0.008 & 2 & 0.668 & 0.698 & 0.063 & 2 & 0.669 & 0.648 & 0.064 & 2 & 0.673 & 0.603 & 0.066 \\
\hline 829 Other mach. op. \& assemblers & 5.20 & 95 & 0.449 & - & 0.005 & 15 & 0.492 & 1.000 & 0.008 & 2 & 0.668 & 0.698 & 0.063 & 2 & 0.669 & 0.648 & 0.064 & 2 & 0.673 & 0.603 & 0.066 \\
\hline 812 Metal-process. plant op. & 5.20 & 81 & 0.436 & - & 0.001 & 23 & 0.503 & 1.000 & 0.004 & 2 & 0.668 & 0.698 & 0.063 & 2 & 0.669 & 0.648 & 0.064 & 2 & 0.673 & 0.603 & 0.066 \\
\hline 823 Rubber \& plastic prod. & 5.20 & 89 & 0.517 & - & 0.003 & 23 & 0.503 & 1.000 & 0.004 & 2 & 0.668 & 0.698 & 0.063 & 2 & 0.669 & 0.648 & 0.064 & 2 & 0.673 & 0.603 & 0.066 \\
\hline 813 Glass, ceramics \& rel. plant op. & 5.20 & 82 & 0.512 & - & 0.000 & - & - & - & - & - & - & - & - & 2 & 0.669 & 0.648 & 0.064 & 2 & 0.673 & 0.603 & 0.066 \\
\hline 743 Textile, garment wo. & 5.20 & 78 & 0.585 & - & 0.001 & 12 & 0.576 & 1.000 & 0.003 & - & - & - & - & - & - & & - & 2 & 0.673 & 0.603 & 0.066 \\
\hline 826 Textile, fur \& leather prod. & 5.20 & 92 & 0.542 & - & 0.002 & 12 & 0.576 & 1.000 & 0.003 & - & - & - & - & - & - & - & - & 2 & 0.673 & 0.603 & 0.066 \\
\hline 314 Ship \& aircraft controllers & 3.30 & 28 & 0.918 & - & 0.003 & 4 & 0.911 & 1.000 & 0.003 & 3 & 0.901 & 0.667 & 0.004 & - & - & & - & - & - & - & \\
\hline 834 Ships' deck crews \& rel. wo. & 3.30 & 99 & 0.771 & - & 0.000 & 4 & 0.911 & 1.000 & 0.003 & 3 & 0.901 & 0.667 & 0.004 & - & - & & - & - & - & - & - \\
\hline 615 Fishery, hunters \& trappers & 3.30 & 63 & 0.733 & - & 0.001 & - & - & - & - & 3 & 0.901 & 0.667 & 0.004 & - & - & & - & - & - & - & - \\
\hline
\end{tabular}


Mapping the social class structure

\begin{tabular}{|c|c|c|c|c|c|c|c|c|c|c|c|c|c|c|c|c|c|c|c|c|c|}
\hline 235 Other teach. prof. & 3.40 & 17 & 0.640 & - & 0.007 & 26 & 0.641 & 1.000 & 0.007 & 4 & 0.705 & 0.667 & 0.018 & - & - & & - & - & - & - & - \\
\hline 348 Religious ass. prof. & 3.40 & 44 & 0.608 & & 0.000 & 26 & 0.641 & 1.000 & 0.007 & 4 & 0.705 & 0.667 & 0.018 & - & - & & - & - & - & - & \\
\hline 232 Sec. education teach. prof. & 3.40 & 14 & 0.719 & & 0.011 & - & - & & & 4 & 0.705 & 0.667 & 0.018 & & & & - & & & & \\
\hline 244 Social sciences \& rel. prof. & 3.50 & 21 & 0.635 & - & 0.007 & 1 & 0.770 & 1.000 & 0.013 & 5 & 0.786 & 0.600 & 0.023 & - & - & & - & - & - & - & - \\
\hline 344 Customs, tax & 3.50 & 40 & 0.672 & - & 0.004 & 1 & 0.770 & 1.000 & 0.013 & 5 & 0.786 & 0.600 & 0.023 & - & - & & - & - & - & - & - \\
\hline 346 Social work ass. prof. & 3.50 & 42 & 0.687 & - & 0.002 & 1 & 0.770 & 1.000 & 0.013 & 5 & 0.786 & 0.600 & 0.023 & - & - & & - & - & - & - & - \\
\hline 111 Legislators & 3.50 & 1 & 0.618 & - & 0.001 & 5 & 0.740 & 1.000 & 0.009 & 5 & 0.786 & 0.600 & 0.023 & - & - & & - & - & - & - & \\
\hline 242 Legal prof. & 3.50 & 19 & 0.747 & - & 0.006 & 5 & 0.740 & 1.000 & 0.009 & 5 & 0.786 & 0.600 & 0.023 & - & - & & - & - & - & - & - \\
\hline $247 \mathrm{Adm}$. of legislation & 3.50 & 24 & 0.569 & & 0.002 & 5 & 0.740 & 1.000 & 0.009 & 5 & 0.786 & 0.600 & 0.023 & & & & - & & & & \\
\hline 332 Pre-primary education teach. & 3.60 & 34 & 0.703 & - & 0.027 & 16 & 0.810 & 1.000 & 0.044 & 6 & 0.818 & 0.833 & 0.046 & - & - & & - & - & - & - & \\
\hline 333 Special education teach. & 3.60 & 35 & 0.644 & - & 0.015 & 16 & 0.810 & 1.000 & 0.044 & 6 & 0.818 & 0.833 & 0.046 & - & - & & - & - & - & - & - \\
\hline 334 Other teach. ass. prof. & 3.60 & 36 & 0.522 & - & 0.002 & 16 & 0.810 & 1.000 & 0.044 & 6 & 0.818 & 0.833 & 0.046 & - & - & & - & - & - & - & - \\
\hline 331 Primary education teach. & 3.60 & 33 & 0.621 & & 0.002 & & - & & & 6 & 0.818 & 0.833 & 0.046 & & & & & & & & \\
\hline 413 Material-recording \& transport & 3.70 & 47 & 0.473 & - & 0.009 & 11 & 0.692 & 1.000 & 0.092 & 7 & 0.750 & 0.811 & 0.147 & - & - & & - & - & - & - & - \\
\hline 414 Library, mail \& rel. Clerks & 3.70 & 48 & 0.496 & - & 0.009 & 11 & 0.692 & 1.000 & 0.092 & 7 & 0.750 & 0.811 & 0.147 & - & - & & - & - & - & - & - \\
\hline 419 Other office clerks & 3.70 & 49 & 0.347 & & 0.004 & 11 & 0.692 & 1.000 & 0.092 & 7 & 0.750 & 0.811 & 0.147 & & & & & & & & \\
\hline 911 Street vendors \& rel. wo. & 3.70 & 100 & 0.409 & & 0.002 & 11 & 0.692 & 1.000 & 0.092 & 7 & 0.750 & 0.811 & 0.147 & - & - & & - & - & - & - & \\
\hline 915 Messengers, porters & 3.70 & 104 & 0.488 & - & 0.004 & 11 & 0.692 & 1.000 & 0.092 & 7 & 0.750 & 0.811 & 0.147 & - & - & & - & - & - & - & - \\
\hline 933 Transport lab. \& freight & 3.70 & 109 & 0.533 & - & 0.019 & 11 & 0.692 & 1.000 & 0.092 & 7 & 0.750 & 0.811 & 0.147 & - & - & & - & - & - & - & - \\
\hline 512 Housekeeping \& restaurant & 3.70 & 53 & 0.643 & - & 0.016 & 17 & 0.644 & 1.000 & 0.016 & 7 & 0.750 & 0.811 & 0.147 & - & - & & - & - & - & - & - \\
\hline 521 Fashion \& other models & 3.70 & 57 & 0.608 & - & 0.000 & 17 & 0.644 & 1.000 & 0.016 & 7 & 0.750 & 0.811 & 0.147 & - & - & & - & - & - & - & \\
\hline 913 Domestic \& rel. Helpers & 3.70 & 102 & 0.612 & - & 0.039 & - & - & - & - & 7 & 0.750 & 0.811 & 0.147 & - & - & & - & - & - & - & \\
\hline 721 Metal moulders, welders & 3.80 & 68 & 0.622 & & 0.009 & 14 & 0.752 & 1.000 & 0.037 & 8 & 0.802 & 0.850 & 0.064 & - & - & & - & - & - & - & - \\
\hline 722 Blacksmiths, toolmakers & 3.80 & 69 & 0.602 & & 0.011 & 14 & 0.752 & 1.000 & 0.037 & 8 & 0.802 & 0.850 & 0.064 & & & & & & & & \\
\hline 723 Mach. mechanics \& fitters & 3.80 & 70 & 0.682 & - & 0.017 & 14 & 0.752 & 1.000 & 0.037 & 8 & 0.802 & 0.850 & 0.064 & - & - & & - & - & - & - & \\
\hline 713 Building finishers & 3.80 & 66 & 0.762 & - & 0.020 & 19 & 0.761 & 1.000 & 0.027 & 8 & 0.802 & 0.850 & 0.064 & - & - & - & - & - & - & - & - \\
\hline 724 Electrical mechanics \& fitters & 3.80 & 71 & 0.513 & - & 0.007 & 19 & 0.761 & 1.000 & 0.027 & 8 & 0.802 & 0.850 & 0.064 & - & - & & - & - & - & - & \\
\hline 422 Client information clerks & 3.90 & 51 & 0.603 & - & 0.008 & 29 & 0.649 & 1.000 & 0.010 & 9 & 0.701 & 0.667 & 0.057 & & - & - & - & - & - & & - \\
\hline 511 Travel attendants \& rel. wo. & 3.90 & 52 & 0.734 & - & 0.003 & 29 & 0.649 & 1.000 & 0.010 & 9 & 0.701 & 0.667 & 0.057 & - & - & - & - & - & - & - & - \\
\hline 411 Secretaries & 3.90 & 45 & 0.683 & - & 0.046 & - & - & - & - & 9 & 0.701 & 0.667 & 0.057 & - & - & & - & - & - & 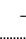 & \\
\hline 341 Finance \& sales ass. prof. & 3.10 & 37 & 0.683 & - & 0.039 & 28 & 0.702 & 1.000 & 0.054 & 10 & 0.713 & 0.667 & 0.059 & - & - & - & - & - & - & & - \\
\hline
\end{tabular}

Toubøl and Grau 
Mapping the social class structure

\begin{tabular}{|c|c|c|c|c|c|c|c|c|c|c|c|c|c|c|c|c|c|c|c|c|c|}
\hline 421 Cashiers, tellers \& rel. clerks & 3.10 & 50 & 0.577 & - & 0.008 & 28 & 0.702 & 1.000 & 0.054 & 10 & 0.713 & 0.667 & 0.059 & - & - & - & - & - & - & - & - \\
\hline 342 Business serv. Agents & 3.10 & 38 & 0.675 & & 0.005 & & & & & 10 & 0.713 & 0.667 & 0.059 & & & & & & & & \\
\hline 311 Physical \& engineering tech. & 3.11 & 25 & 0.701 & - & 0.023 & 31 & 0.732 & 1.000 & 0.031 & 11 & 0.790 & 0.833 & 0.051 & - & - & - & - & - & - & - & - \\
\hline 315 Safety \& quality inspectors & 3.11 & 29 & 0.604 & - & 0.002 & 31 & 0.732 & 1.000 & 0.031 & 11 & 0.790 & 0.833 & 0.051 & - & - & - & - & - & - & - & - \\
\hline 321 Life science tech. & 3.11 & 30 & 0.738 & - & 0.006 & 31 & 0.732 & 1.000 & 0.031 & 11 & 0.790 & 0.833 & 0.051 & - & - & & - & - & - & - & - \\
\hline 214 Architects \& engineers & 3.11 & 9 & 0.766 & - & 0.020 & - & - & - & - & 11 & 0.790 & 0.833 & 0.051 & - & - & - & - & - & - & - & - \\
\hline 734 Printing \& rel. trades wo. & 3.12 & 75 & 0.621 & - & 0.003 & 3 & 0.697 & 1.000 & 0.006 & 12 & 0.680 & 0.667 & 0.006 & - & - & - & - & - & & - & - \\
\hline 825 Printing, binding \& paper & 3.12 & 91 & 0.594 & - & 0.003 & 3 & 0.697 & 1.000 & 0.006 & 12 & 0.680 & 0.667 & 0.006 & - & - & - & - & - & - & - & - \\
\hline 814 Wood process. \& papermaking & 3.12 & 83 & 0.448 & - & 0.000 & - & - & & - & 12 & 0.680 & 0.667 & 0.006 & - & - & - & - & - & - & - & - \\
\hline 611 Market gardeners \& crop & 3.13 & 59 & 0.682 & - & 0.004 & 8 & 0.664 & 1.000 & 0.007 & 13 & 0.730 & 0.600 & 0.021 & - & - & - & - & - & - & - & - \\
\hline 614 Forestry \& rel. wo. & 3.13 & 62 & 0.594 & - & 0.001 & 8 & 0.664 & 1.000 & 0.007 & 13 & 0.730 & 0.600 & 0.021 & - & - & - & - & - & - & - & - \\
\hline 921 Agriculture, fishery \& rel. lab. & 3.13 & 106 & 0.528 & - & 0.002 & 8 & 0.664 & 1.000 & 0.007 & 13 & 0.730 & 0.600 & 0.021 & & & & - & & & & \\
\hline 612 Market-oriented animal prod. & 3.13 & 60 & 0.625 & - & 0.005 & 32 & 0.752 & 1.000 & 0.014 & 13 & 0.730 & 0.600 & 0.021 & - & - & - & - & - & - & - & - \\
\hline 613 Market-oriented crop \& animal & 3.13 & 61 & 0.738 & - & 0.010 & 32 & 0.752 & 1.000 & 0.014 & 13 & 0.730 & 0.600 & 0.021 & - & - & & - & - & - & - & - \\
\hline 212 Math \& stat. prof. & 3.14 & 7 & 0.529 & & 0.000 & 27 & 0.706 & 1.000 & 0.050 & 14 & 0.723 & 0.650 & 0.066 & & & & & & & & \\
\hline 241 Business prof. & 3.14 & 18 & 0.637 & - & 0.018 & 27 & 0.706 & 1.000 & 0.050 & 14 & 0.723 & 0.650 & 0.066 & - & - & - & - & - & - & - & - \\
\hline 343 Administrative ass. prof. & 3.14 & 39 & 0.665 & - & 0.031 & 27 & 0.706 & 1.000 & 0.050 & 14 & 0.723 & 0.650 & 0.066 & - & - & - & - & - & - & - & - \\
\hline 121 Directors \& chief executives & 3.14 & 2 & 0.679 & & 0.005 & 30 & 0.648 & 1.000 & 0.016 & 14 & 0.723 & 0.650 & 0.066 & & & & & & & & \\
\hline 123 Other departmental managers & 3.14 & 4 & 0.614 & - & 0.011 & 30 & 0.648 & 1.000 & 0.016 & 14 & 0.723 & 0.650 & 0.066 & - & - & - & - & - & - & - & - \\
\hline 245 Writers \& performing artists & 2.60 & 22 & 0.701 & - & 0.006 & 6 & 0.727 & 1.000 & 0.012 & - & & - & - & - & - & - & - & - & - & - & - \\
\hline $\begin{array}{l}313 \text { Optical \& electronic } \\
\text { equipment }\end{array}$ & 2.60 & 27 & 0.686 & - & 0.003 & 6 & 0.727 & 1.000 & 0.012 & - & - & - & - & - & - & - & - & - & - & - & - \\
\hline 347 Artistic, entertainment & 2.60 & 43 & 0.618 & & 0.003 & 6 & 0.727 & 1.000 & 0.012 & & & & & & & & & & & & \\
\hline 213 Computing prof. & 2.70 & 8 & 0.666 & - & 0.011 & 7 & 0.770 & 1.000 & 0.021 & - & - & - & - & - & - & - & - & - & - & - & - \\
\hline 312 Computer ass. prof. & 2.70 & 26 & 0.627 & - & 0.009 & 7 & 0.770 & 1.000 & 0.021 & - & - & - & - & - & - & - & - & - & - & - & - \\
\hline 211 Nat. Science prof. & 2.90 & 6 & 0.524 & - & 0.001 & 9 & 0.848 & 1.000 & 0.023 & - & - & - & - & - & - & - & - & - & - & - & - \\
\hline 221 Life science prof. & 2.90 & 10 & 0.562 & & 0.002 & 9 & 0.848 & 1.000 & 0.023 & & & & & & & & & & & & \\
\hline 222 Health prof. (except nursing) & 2.90 & 11 & 0.922 & - & 0.013 & 9 & 0.848 & 1.000 & 0.023 & - & - & - & - & - & - & - & - & - & - & - & - \\
\hline 231 Higher education teach. Prof. & 2.90 & 13 & 0.613 & - & 0.007 & 9 & 0.848 & 1.000 & 0.023 & - & - & - & - & - & - & - & - & - & - & - & - \\
\hline 223 Nursing \& midwifery & 2.20 & 12 & 0.725 & - & 0.005 & 20 & 0.860 & 1.000 & 0.029 & - & - & - & - & - & - & - & - & - & - & - & - \\
\hline 323 Nursing \& midwifery ass. prof. & 2.20 & 32 & 0.822 & - & 0.024 & 20 & 0.860 & 1.000 & 0.029 & - & - & - & - & - & - & - & - & - & - & - & - \\
\hline 233 Primary education teach. prof. & 2.21 & 15 & 0.741 & - & 0.038 & 21 & 0.750 & 1.000 & 0.039 & - & - & - & - & - & - & - & - & - & - & - & - \\
\hline 234 Special education teach. Prof. & 2.21 & 16 & 0.468 & - & 0.001 & 21 & 0.750 & 1.000 & 0.039 & - & - & - & - & - & - & - & - & - & - & - & - \\
\hline
\end{tabular}


Mapping the social class structure

\begin{tabular}{|c|c|c|c|c|c|c|c|c|c|c|c|c|c|c|c|c|c|c|c|c|c|}
\hline 122 Prod. \& operations managers & 2.22 & 3 & 0.567 & - & 0.012 & 22 & 0.617 & 1.000 & 0.024 & - & - & - & - & - & - & - & - & - & - & - & - \\
\hline 131 General managers & 2.22 & 5 & 0.427 & & 0.012 & 22 & 0.617 & 1.000 & 0.024 & - & & - & - & - & - & - & & - & - & - & - \\
\hline 816 Power prod. & 2.25 & 85 & 0.679 & - & 0.001 & 25 & 0.652 & 1.000 & 0.011 & - & - & - & - & - & - & - & - & - & - & - & - \\
\hline 914 Building caretakers & 2.25 & 103 & 0.645 & - & 0.010 & 25 & 0.652 & 1.000 & 0.011 & - & - & - & - & - & - & - & - & - & - & - & - \\
\hline 243 Librarians \& rel. prof. & 1.20 & 20 & 0.709 & & 0.002 & & - & - & - & & & & & & - & & & & & & - \\
\hline 246 Religious prof. & 1.23 & 23 & 0.935 & - & 0.001 & - & - & - & - & - & - & - & - & - & - & - & - & - & - & - & - \\
\hline 322 Modern health ass. prof. & 1.31 & 31 & 0.820 & - & 0.015 & - & - & - & - & - & - & - & - & - & - & - & - & - & - & - & - \\
\hline 345 Police inspectors \& detectives & 1.41 & 41 & 0.893 & - & 0.001 & - & - & - & - & - & - & - & - & - & - & - & - & - & - & - & - \\
\hline 513 Personal care \& rel. wo. & 1.54 & 54 & 0.740 & - & 0.102 & - & - & - & - & - & - & - & - & - & - & - & - & - & - & - & - \\
\hline 514 Other personal service wo. & 1.55 & 55 & 0.771 & - & 0.006 & - & - & - & - & - & - & - & - & - & - & - & - & - & - & - & - \\
\hline 516 Protective serv. wo. & 1.56 & 56 & 0.632 & - & 0.009 & - & - & - & - & - & - & - & - & - & - & - & - & - & - & - & - \\
\hline 714 Painters & 1.67 & 67 & 0.829 & & 0.008 & - & - & - & & - & & - & - & - & - & - & & - & - & - & - \\
\hline 731 Precision wo. in metal & 1.72 & 72 & 0.625 & & 0.001 & & - & - & & - & & & & - & - & & & & & - & - \\
\hline 732 Potters, glass-makers & 1.73 & 73 & 0.657 & - & 0.000 & - & - & - & - & - & - & - & - & - & - & - & - & - & - & - & - \\
\hline 744 Leather \& shoemaking & 1.79 & 79 & 0.653 & - & 0.000 & - & - & - & - & - & - & - & - & - & - & - & - & - & - & - & - \\
\hline 831 Locomotive engine-drivers & 1.96 & 96 & 0.694 & - & 0.001 & - & - & - & - & - & - & - & - & - & - & - & - & - & - & - & - \\
\hline 912 Shoe cleaning & 1.10 & 101 & 0.500 & - & 0.000 & - & - & - & - & - & - & - & - & - & - & - & - & - & - & - & - \\
\hline
\end{tabular}




\section{Appendix C: Reliability tests of MONECA}

We perform three tests of the reliability of the methodological approach we have presented in this paper. These tests are concerned with the RR cut point of the minimum cell-frequency threshold, and sensitivity to changes in the data-input.

First, we test for the robustness with regard to the chosen cut point of an $R R=1$. This cut point is not arbitrary, as the assumption of randomness reflects the ideal of perfect mobility. Nonetheless, it is problematic for the reliability of the instrument if the cluster solution is sensitive to small variations in the cut point. On the other hand, we would expect large variation to significantly impact the solution.

Figure C1. Relative Risk cut point test results

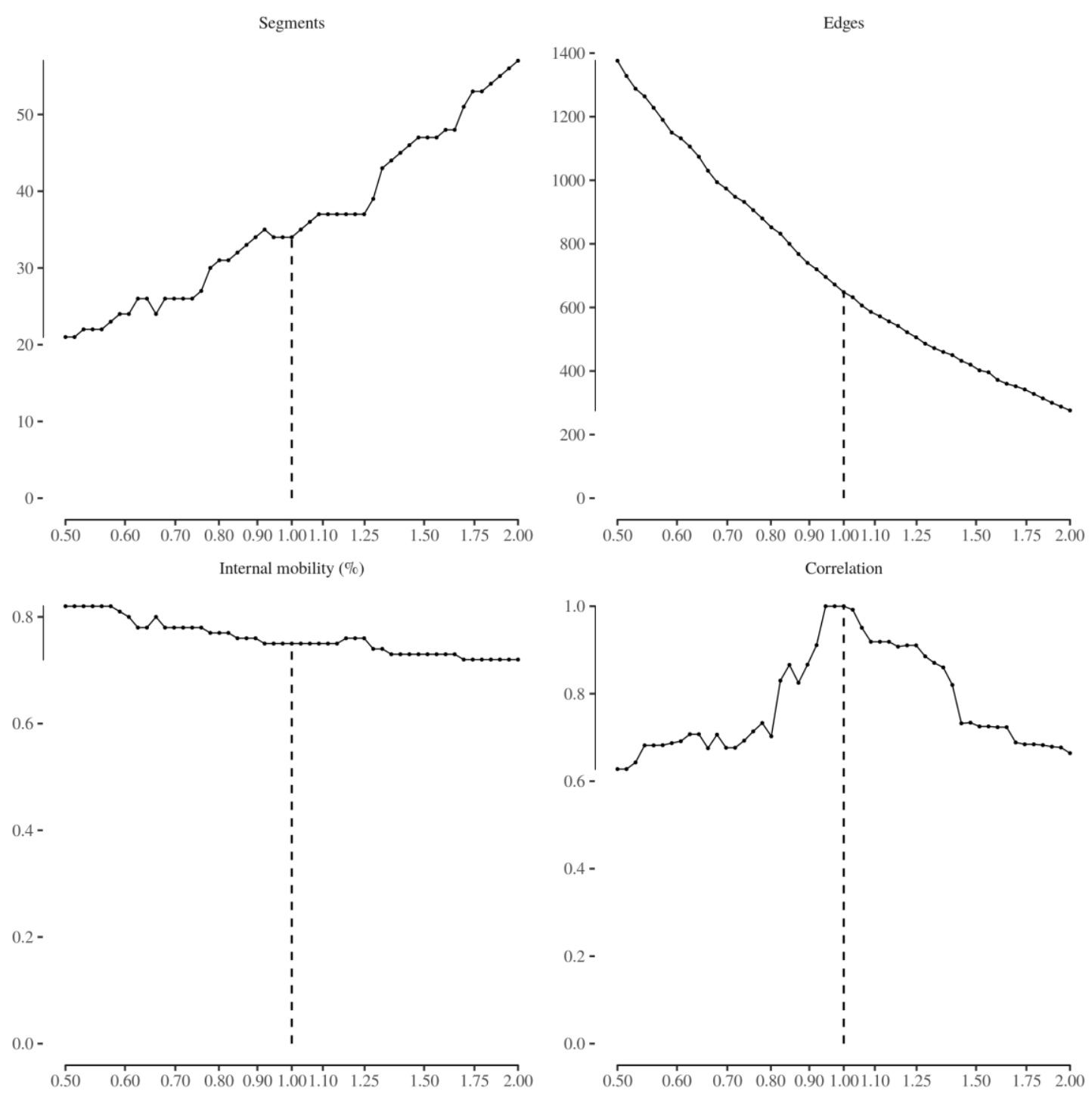

Figure $\mathrm{C} 1$ presents the results of the test of the robustness when varying the RR cut point. The four graphs show, respectively, 1) the change in number of edges, 2) the change in number of clusters of the final solution, 3) the amount of total mobility within the clusters of the final solution (i.e. mobility explained), 4) and the 
correlation of the cluster solution with the solution of an $R R=1$. The drop line indicates the solution when the RR cut point $=1$. As expected, the number of edges are affected dramatically by variation in the cut point. However, the number of clusters is quite stable around the original solution of 34 clusters, spanning from 30 to 37 within the $0.75 \leq \mathrm{RR} \leq 1.2$ interval. There is only little change with regard to the amount of mobility within the clusters. Finally, the correlation coefficient never goes below 0.6 within the entire test-interval of $0.5 \leq \mathrm{RR} \leq 2.0$. Within $0.825 \leq \mathrm{RR} \leq 1.3$ it never drops under 0.8 , meaning $80 \%$ of the occupations are connected to, and separated from, the same clusters by virtue of the cluster boundaries of the final solution, when comparing with the solution of an $R R=1$. These results suggest that the algorithm is quite robust, despite the dramatic effect on the number of edges when varying the RR.

Figure C2. Minimum cell frequency threshold test results
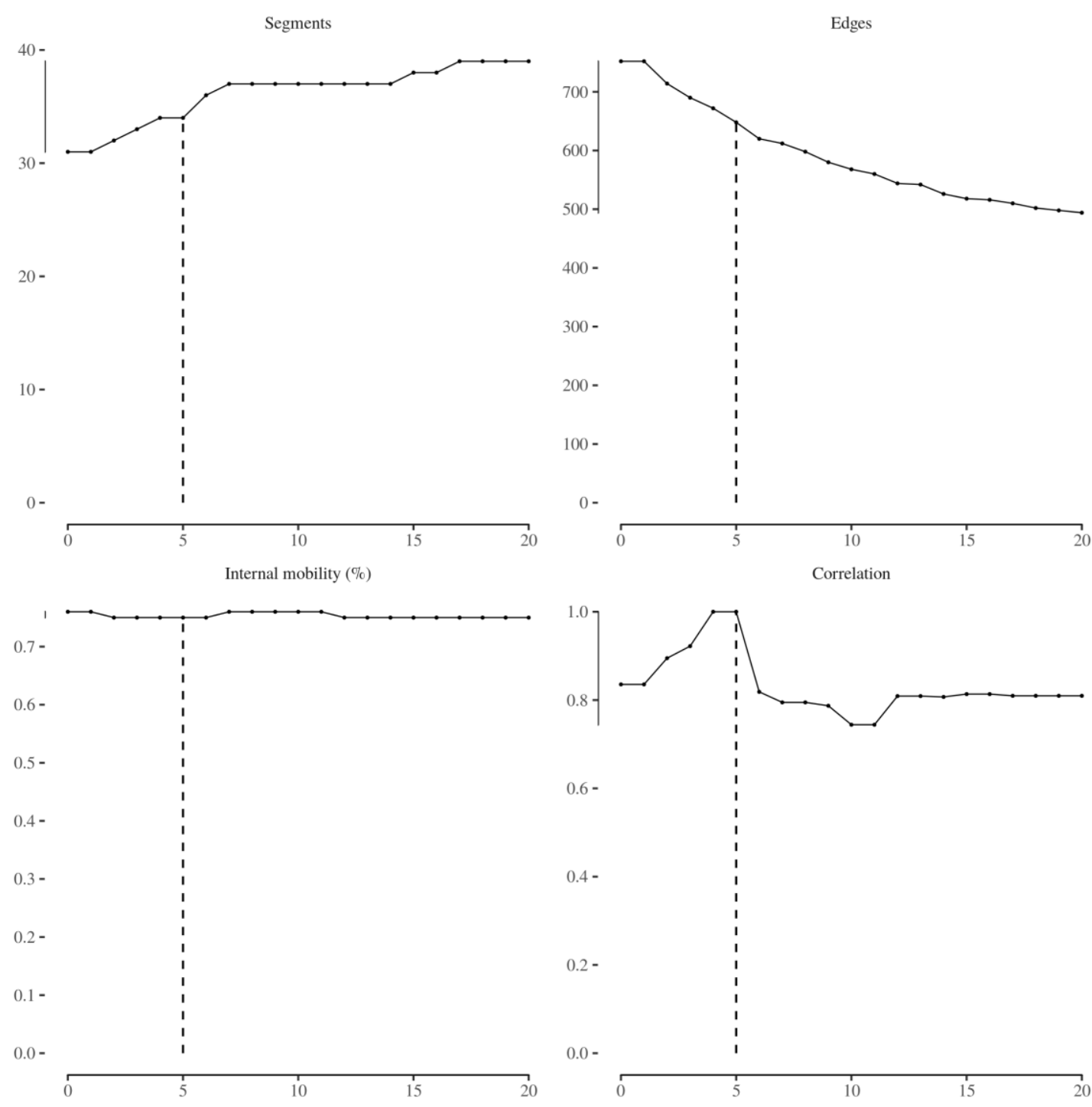

Second, in the same manner we test the threshold for including ties of a minimum cell frequency of five. This threshold is more critical as there are no substantial theoretical considerations underpinning it, in contrast to what was the case with regard to the RR cut point. Thus, the choice of threshold rests on the researcher's inspection of what is necessary in order to exclude ties based on a relatively small number of observations that 
seem unreasonable according to substantial knowledge of the mobility structure under scrutiny. That is, we need to exclude ties based on a small number of observations, which we suspect to be the result of errors in measurement. This entails an aspect of subjectivity, and it would certainly be preferable if the derived cluster solutions are rather similar irrespective of this threshold. When inspecting figure $\mathrm{C} 2$, which is similar to figure $\mathrm{C} 1$ except for the $\mathrm{X}$-axis representing variation in the minimum cell frequency threshold, we find only relatively small variation in the dependent measures. Thus, despite the subjective aspect in the choice of cut point, the algorithm produces very similar solutions, as is evident from the fact that the correlation with a solution of a threshold of 5 remains around 0.8 in the entire interval from 0 to 20 .

Figure C3. Exclusion of nodes test results

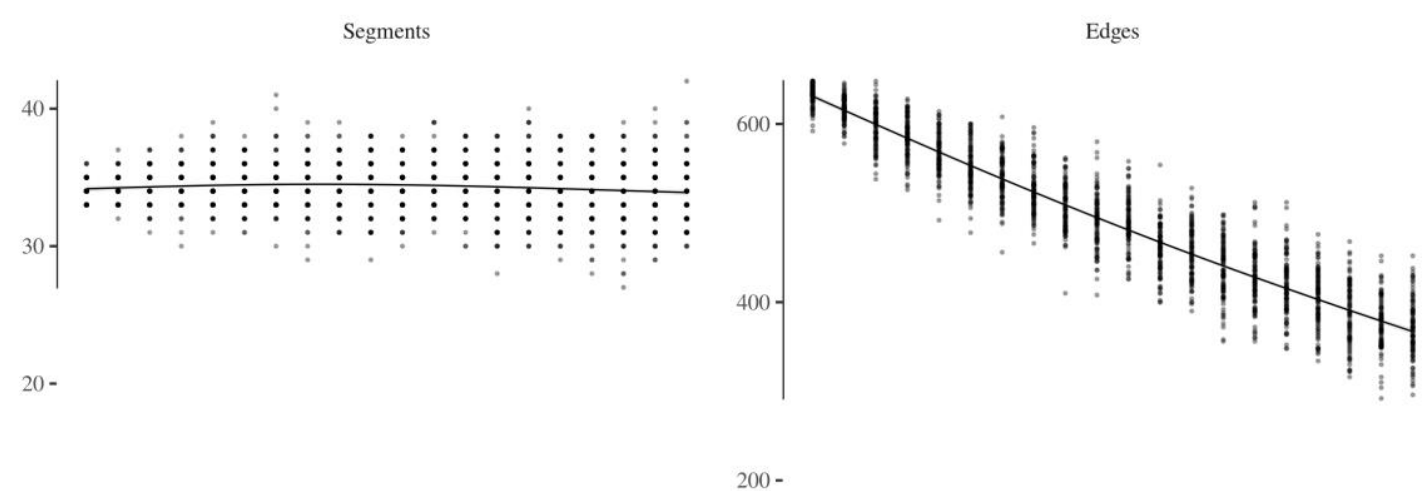

$10-$

0

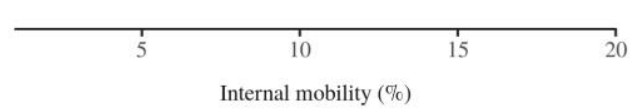

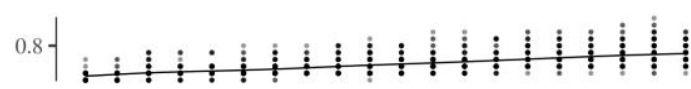

0.6 -

0.4 -

0.2 -

$0.0-$

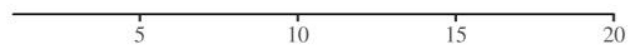

0 -
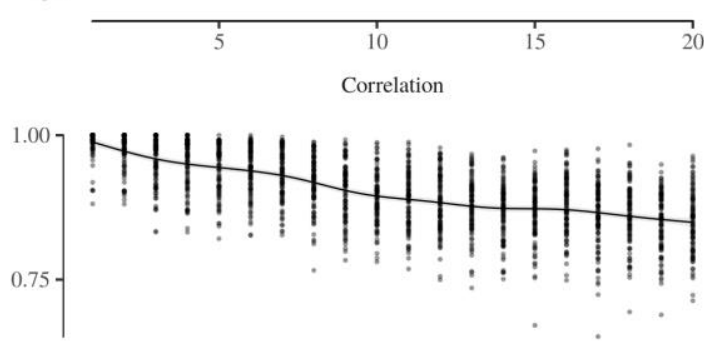

$0.50-$

0.25 -

$0.00-$

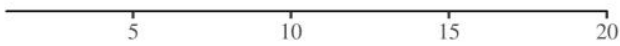

Thirdly, we test the robustness of the MONECA algorithm by comparing the final solution with cluster solutions of networks in which we have deleted randomly chosen occupations. Figure C3 summarises the test results. This was done in order to assess the algorithm's ability to consistently reproduce the results when changing the underlying data structure. Even though it would be preferable to test by comparing the results of different datasets of labour market mobility, or different occupational classifications of the same data, the tests 
mimics such scenarios. In fact, it could be argued that removing parts of the table/network is a more challenging test than changing the data source or the classification, since the algorithm is based on the assumption that the data perfectly represents reality.

Because the mobility table is transformed into a network, removing any occupations/nodes may, in principle, affect the relations of all the remaining occupations/nodes. Thus, the changes to the data structure when deleting network nodes may be quite substantial. We deleted 1 to 20 occupations, and iterated the process 100 times. In total, 2000 reduced networks and subsequent cluster solutions were produced and compared with the solution of the full network. The full network consists of 109 occupations, meaning that removing 20 occupations is equal to deleting $18.3 \%$ of the nodes in the network. As can be seen from the lower right graph in figure C3, the average correlation is never lower than 0.9 and the lowest single correlation out of 2000 is at 0.65. This is reassuring with regard to the reliability of the cluster solution of the full network. It also suggests that MONECA may be rather robust across different data inputs varying in source and occupational classification. 
Appendix D. Occupations by income, share of women, education and union density in 2007

\begin{tabular}{|c|c|c|c|c|c|}
\hline Occupation & Final cluster & Disp. income (DKK) & Education (Years) & Share of women & Union density \\
\hline 733 Handicraft wo. in wood, textile \& rel. mat. & 5.20 & 179,692 & 11.5 & $44.9 \%$ & $79.6 \%$ \\
\hline 741 Food proces. \& rel. trades wo. & 5.20 & 168,692 & 11.8 & $34.4 \%$ & $65.1 \%$ \\
\hline 742 Wood treaters \& rel. trades wo. & 5.20 & 171,683 & 11.5 & $16.5 \%$ & $80.6 \%$ \\
\hline 743 Textile, garment \& rel. trades wo. & 5.20 & 165,304 & 11.5 & $62.8 \%$ & $72.2 \%$ \\
\hline 812 Metal-proces. plant op. & 5.20 & 188,245 & 10.9 & $13.1 \%$ & $85.9 \%$ \\
\hline 813 Glass. ceramics \& rel. plant op. & 5.20 & 201,708 & 10.8 & $15.3 \%$ & $89.1 \%$ \\
\hline 815 Chemical proces. plant op. & 5.20 & 219,256 & 11.6 & $25.0 \%$ & $89.9 \%$ \\
\hline 817 Automated assembly-line \& industrial robot op. & 5.20 & 196,744 & 11.2 & $23.5 \%$ & $80.0 \%$ \\
\hline 821 Metal \& mineral products mach. op. & 5.20 & 188,259 & 11.1 & $19.2 \%$ & $87.7 \%$ \\
\hline 822 Chemical products mach. op. & 5.20 & 192,938 & 11.1 & $23.8 \%$ & $81.7 \%$ \\
\hline 823 Rubber \& plastic products mach. op. & 5.20 & 187,101 & 11.1 & $30.6 \%$ & $82.8 \%$ \\
\hline 824 Wood products mach. op. & 5.20 & 175,999 & 11.1 & $19.9 \%$ & $84.1 \%$ \\
\hline 826 Textile. fur \& leather products mach. op. & 5.20 & 179,634 & 10.7 & $57.2 \%$ & $85.6 \%$ \\
\hline 827 Food \& rel. products mach. op. & 5.20 & 192,858 & 11.2 & $31.2 \%$ & $92.1 \%$ \\
\hline 828 Assemblers & 5.20 & 179,960 & 11.1 & $53.6 \%$ & $87.0 \%$ \\
\hline 829 Other mach. op. \& assemblers & 5.20 & 179,360 & 11.1 & $44.2 \%$ & $81.3 \%$ \\
\hline 932 Manufacturing lab. & 5.20 & 162,276 & 10.8 & $37.6 \%$ & $69.2 \%$ \\
\hline 711 Miners. shot-firers. stonecutters \& carvers & 5.10 & 198,132 & 11.6 & $2.7 \%$ & $67.4 \%$ \\
\hline 712 Building frame \& rel. trades wo. & 5.10 & 190,370 & 12.2 & $1.0 \%$ & $76.3 \%$ \\
\hline 811 Mining \& mineral-proces. plant op. & 5.10 & 284,483 & 12.6 & $2.9 \%$ & $79.1 \%$ \\
\hline 832 Motor vehicle drivers & 5.10 & 204,378 & 10.8 & $5.7 \%$ & $79.0 \%$ \\
\hline 833 Agri. \& other mobile plant op. & 5.10 & 200,352 & 10.6 & $4.7 \%$ & $84.2 \%$ \\
\hline 916 Garbage collectors \& rel. lab. & 5.10 & 193,969 & 10.8 & $4.8 \%$ & $73.3 \%$ \\
\hline 931 Mining \& construction lab. & 5.10 & 191,344 & 10.6 & $5.3 \%$ & $80.7 \%$ \\
\hline 411 Secretaries \& keyboard-operating clerks & 3.90 & 194,636 & 12.7 & $83.9 \%$ & $74.7 \%$ \\
\hline 422 Client information clerks & 3.90 & 182,026 & 12.4 & $83.6 \%$ & $67.2 \%$ \\
\hline 511 Travel attendants \& rel. wo. & 3.90 & 199,486 & 12.1 & $61.3 \%$ & $62.5 \%$ \\
\hline 713 Building finishers \& rel. trades wo. & 3.80 & 198,297 & 12.6 & $1.1 \%$ & $81.1 \%$ \\
\hline 721 Metal moulders. welders \& rel. trades wo. & 3.80 & 200,566 & 12.2 & $2.7 \%$ & $88.1 \%$ \\
\hline 722 Blacksmiths. toolmakers \& rel. trades wo. & 3.80 & 204,120 & 12.5 & $2.8 \%$ & $87.1 \%$ \\
\hline 723 mach. mechanics \& fitters & 3.80 & 212,477 & 12.6 & $2.5 \%$ & $83.3 \%$ \\
\hline 724 Electrical mechanics \& fitters & 3.80 & 200,638 & 12.4 & $7.3 \%$ & $82.6 \%$ \\
\hline 413 Material-recording \& transport clerks & 3.70 & 186,732 & 11.9 & $45.5 \%$ & $67.7 \%$ \\
\hline 414 Library. mail \& rel. Clerks & 3.70 & 155,827 & 11.5 & $37.0 \%$ & $68.3 \%$ \\
\hline 419 Other office clerks & 3.70 & 148,883 & 12.1 & $68.2 \%$ & $53.5 \%$ \\
\hline 512 Housekeeping \& restaurant serv. wo. & 3.70 & 140,114 & 11.5 & $65.1 \%$ & $50.5 \%$ \\
\hline 521 Fashion \& other models & 3.70 & 132,978 & 11.9 & $67.4 \%$ & $23.4 \%$ \\
\hline 522 Shop salespersons \& demonstrators & 3.70 & 115,193 & 11.2 & $59.6 \%$ & $40.0 \%$ \\
\hline 911 Street vendors \& rel. wo. & 3.70 & 123,657 & 12.1 & $50.3 \%$ & $36.6 \%$ \\
\hline 913 Domestic \& rel. Helpers. cleaners \& launderers & 3.70 & 140,881 & 10.6 & $74.4 \%$ & $59.4 \%$ \\
\hline 915 Messengers. porters. doorkeepers \& rel. wo. & 3.70 & 103,991 & 10.6 & $35.8 \%$ & $29.1 \%$ \\
\hline 933 Transport lab. \& freight handlers & 3.70 & 132,202 & 10.7 & $27.1 \%$ & $48.6 \%$ \\
\hline 331 Primary education teach. ass. prof. & 3.60 & 209,019 & 13.9 & $93.5 \%$ & $93.6 \%$ \\
\hline 332 Pre-primary education teach. ass. prof. & 3.60 & 190,902 & 14.4 & $86.0 \%$ & $92.0 \%$ \\
\hline 333 Special education teach. ass. prof. & 3.60 & 190,741 & 14.1 & $76.0 \%$ & $87.3 \%$ \\
\hline 334 Other teach. ass. prof. & 3.60 & 192,953 & 13.1 & $47.2 \%$ & $69.9 \%$ \\
\hline 111 Legislators & 3.50 & 413,478 & 14.6 & $15.2 \%$ & $87.9 \%$ \\
\hline 242 Legal prof. & 3.50 & 312,539 & 16.7 & $53.0 \%$ & $88.7 \%$ \\
\hline 244 Social sciences \& rel. prof. & 3.50 & 254,424 & 16.4 & $63.8 \%$ & $87.2 \%$ \\
\hline $247 \mathrm{Adm}$. of legislation in public sector & 3.50 & 270,004 & 15.5 & $49.8 \%$ & $91.6 \%$ \\
\hline 344 Customs. tax \& rel. gov. ass. prof. & 3.50 & 219,146 & 13.4 & $79.0 \%$ & $92.4 \%$ \\
\hline 346 Social work ass. prof. & 3.50 & 213,602 & 14.7 & $82.0 \%$ & $89.7 \%$ \\
\hline 232 Sec. education teach. prof. & 3.40 & 279,033 & 15.8 & $44.3 \%$ & $93.2 \%$ \\
\hline 235 Other teach. prof. & 3.40 & 228,657 & 14.8 & $55.4 \%$ & $76.4 \%$ \\
\hline 348 Religious ass. prof. & 3.40 & 189,930 & 13.2 & $57.7 \%$ & $63.0 \%$ \\
\hline
\end{tabular}


Mapping the social class structure

\begin{tabular}{|c|c|c|c|c|c|}
\hline 314 Ship \& aircraft controllers \& tech.* & 3.30 & 338,274 & 13.2 & $10.8 \%$ & $60.1 \%$ \\
\hline 615 Fishery wo.. hunters \& trappers & 3.30 & 346,832 & 11.1 & $4.2 \%$ & $45.2 \%$ \\
\hline 834 Ships' deck crews \& rel. wo. & 3.30 & 231,192 & 11.2 & $3.7 \%$ & $45.5 \%$ \\
\hline 121 Directors \& chief executives & 3.14 & 463,826 & 14.2 & $23.4 \%$ & $61.7 \%$ \\
\hline 123 Other departmental managers & 3.14 & 317,094 & 14.1 & $31.9 \%$ & $71.4 \%$ \\
\hline 212 Math \& stat. Prof. & 3.14 & 325,706 & 16.2 & $35.4 \%$ & $61.1 \%$ \\
\hline 241 Business prof. & 3.14 & 303,843 & 14.7 & $43.2 \%$ & $65.1 \%$ \\
\hline 343 Administrative ass. prof. & 3.14 & 238,826 & 13.1 & $72.0 \%$ & $76.1 \%$ \\
\hline 611 Market gardeners \& crop growers & 3.13 & 184,559 & 12.0 & $28.4 \%$ & $74.8 \%$ \\
\hline 612 Market-oriented animal prod. \& rel. wo. & 3.13 & 320,369 & 11.9 & $33.3 \%$ & $47.7 \%$ \\
\hline 613 Market-oriented crop \& animal prod. & 3.13 & 293,979 & 12.2 & $12.3 \%$ & $35.8 \%$ \\
\hline 614 Forestry \& rel. wo. & 3.13 & 226,335 & 11.4 & $8.2 \%$ & $75.2 \%$ \\
\hline 921 agriculture. fishery \& rel. lab. & 3.13 & 163,450 & 10.8 & $32.9 \%$ & $63.6 \%$ \\
\hline 734 Printing \& rel. trades wo. & 3.12 & 228,120 & 12.8 & $29.3 \%$ & $79.3 \%$ \\
\hline 814 Wood proces. \& papermaking plant op. & 3.12 & 190,686 & 11.2 & $21.0 \%$ & $84.1 \%$ \\
\hline 825 Printing. binding \& paper products mach. op. & 3.12 & 218,735 & 11.6 & $15.8 \%$ & $91.2 \%$ \\
\hline 214 Architects \& engineers & 3.11 & 299,033 & 15.8 & $19.9 \%$ & $74.7 \%$ \\
\hline 311 Physical \& engineering science tech. & 3.11 & 244,970 & 13.5 & $29.0 \%$ & $79.6 \%$ \\
\hline 315 Safety \& quality inspectors & 3.11 & 243,581 & 13.3 & $32.7 \%$ & $82.6 \%$ \\
\hline 321 Life science tech. \& rel. ass. prof. & 3.11 & 222,353 & 14.5 & $78.5 \%$ & $85.2 \%$ \\
\hline 341 Finance \& sales ass. prof. & 3.10 & 272,895 & 13.3 & $40.5 \%$ & $70.4 \%$ \\
\hline 342 Business serv. agents \& trade brokers & 3.10 & 230,026 & 12.9 & $45.4 \%$ & $55.7 \%$ \\
\hline 412 Numerical clerks & 3.10 & 221,665 & 12.9 & $76.2 \%$ & $70.8 \%$ \\
\hline 421 Cashiers. tellers \& rel. Clerks & 3.10 & 196,852 & 12.7 & $78.1 \%$ & $82.0 \%$ \\
\hline 211 Nat. Science prof. & 2.90 & 304,594 & 17.0 & $33.8 \%$ & $66.3 \%$ \\
\hline 221 Life science prof. & 2.90 & 265,153 & 17.1 & $47.9 \%$ & $79.8 \%$ \\
\hline 222 Health prof. (except nursing) & 2.90 & 351,334 & 17.1 & $55.0 \%$ & $88.9 \%$ \\
\hline 231 Higher education teach. prof. & 2.90 & 289,422 & 17.5 & $38.1 \%$ & $76.0 \%$ \\
\hline 213 Computing prof. & 2.70 & 297,456 & 14.3 & $20.0 \%$ & $61.8 \%$ \\
\hline 312 Computer ass. prof. & 2.70 & 263,205 & 13.5 & $21.7 \%$ & $68.5 \%$ \\
\hline 245 Writers \& performing artists & 2.60 & 245,041 & 14.7 & $43.7 \%$ & $77.0 \%$ \\
\hline 313 Optical \& electronic equipment op. & 2.60 & 222,804 & 13.4 & $43.7 \%$ & $55.7 \%$ \\
\hline 347 Artistic. entertainment \& sports ass. prof. & 2.60 & 194,807 & 13.1 & $52.5 \%$ & $51.8 \%$ \\
\hline 816 Power prod. \& rel. plant op. & 2.25 & 277,178 & 12.3 & $3.2 \%$ & $90.6 \%$ \\
\hline 914 Building caretakers. window \& rel. Cleaners & 2.25 & 182,557 & 11.6 & $10.8 \%$ & $74.4 \%$ \\
\hline 122 Prod. \& operations managers & 2.22 & 587,889 & 14.2 & $31.1 \%$ & $78.7 \%$ \\
\hline 131 General managers & 2.22 & 490,870 & 13.5 & $45.8 \%$ & $71.2 \%$ \\
\hline 233 Primary education teach. prof. & 2.21 & 215,816 & 15.3 & $66.6 \%$ & $85.5 \%$ \\
\hline 234 Special education teach. prof. & 2.21 & 247,283 & 15.3 & $65.2 \%$ & $91.2 \%$ \\
\hline 223 Nursing \& midwifery & 2.20 & 250,498 & 15.8 & $96.3 \%$ & $95.2 \%$ \\
\hline 323 Nursing \& midwifery ass. prof. & 2.20 & 212,113 & 14.9 & $95.3 \%$ & $92.8 \%$ \\
\hline 831 Locomotive engine-drivers \& rel. wo. & 1.96 & 231,657 & 12.7 & $4.5 \%$ & $97.9 \%$ \\
\hline 744 Leather \& shoemaking trades wo. & 1.79 & 206,694 & 11.8 & $38.8 \%$ & $70.5 \%$ \\
\hline 732 Potters. glass-makers \& rel. trades wo. & 1.73 & 170,028 & 11.3 & $63.6 \%$ & $77.7 \%$ \\
\hline 731 Precision wo. in metal \& rel. mat. & 1.72 & 192,225 & 12.5 & $55.4 \%$ & $65.1 \%$ \\
\hline 714 Painters. building structure cleaners \& rel. trade wo. & 1.67 & 181,745 & 11.8 & $26.9 \%$ & $77.7 \%$ \\
\hline 516 Protective serv. wo. & 1.56 & 222,799 & 12.7 & $13.6 \%$ & $95.2 \%$ \\
\hline 514 Other personal service wo. & 1.55 & 145,392 & 12.0 & $86.3 \%$ & $63.3 \%$ \\
\hline 513 Personal care \& rel. wo. & 1.54 & 164,446 & 11.6 & $87.8 \%$ & $77.0 \%$ \\
\hline 345 Police inspectors \& detectives & 1.41 & 274,551 & 13.6 & $2.9 \%$ & $98.6 \%$ \\
\hline 322 Modern health ass. prof. (except nursing) & 1.31 & 191,830 & 13.8 & $91.3 \%$ & $88.7 \%$ \\
\hline 246 Religious prof. & 1.23 & 224,456 & 16.3 & $44.7 \%$ & $82.3 \%$ \\
\hline 243 Librarians \& rel. information prof. & 1.20 & 215,744 & 14.9 & $75.1 \%$ & $83.6 \%$ \\
\hline 912 Shoe cleaning \& other street serv. & 1.10 & 178,708 & 11.6 & $4.3 \%$ & $78.7 \%$ \\
\hline Total & & 201,538 & 12.7 & $51.5 \%$ & $74.1 \%$ \\
\hline
\end{tabular}

* The very low mean years of education is due to a data error. Aircraft pilots and air traffic controllers are for reasons unknown registered with untealistically short educations in the registers of Statistics Denmark (Albæk and Thomsen, 2011: 28). 
Appendix E. Income statistics of clusters in 2007 (DKK)

\begin{tabular}{|c|c|c|c|c|c|c|}
\hline \multirow{2}{*}{$\#$} & \multicolumn{4}{|c|}{ Disposable income } & \multicolumn{2}{|c|}{ Standard disposable income } \\
\hline & Mean & $1^{\text {st }}$ quartile & Median & $3^{\text {rd }}$ quartile & Mean & Median \\
\hline $2.22 * *$ & 573,365 & 207,441 & 264,893 & 366,065 & 390,762 & 284,020 \\
\hline 3.3 & 324,543 & 225,476 & 292,407 & 389,893 & 335,398 & 314,777 \\
\hline 2.9 & 319,998 & 242,145 & 295,656 & 372,783 & 314,088 & 296,391 \\
\hline 2.7 & 283,378 & 227,417 & 273,123 & 327,252 & 300,512 & 286,266 \\
\hline 1.41 & 274,551 & 243,353 & 265,612 & 298,121 & 259,158 & 256,705 \\
\hline 3.11 & 263,466 & 209,732 & 248,553 & 298,085 & 279,297 & 266,050 \\
\hline 3.14 & 260,838 & 204,497 & 241,252 & 290,369 & 313,082 & 278,342 \\
\hline 3.5 & 259,903 & 201,841 & 240,659 & 290,447 & 294,666 & 262,807 \\
\hline 3.4 & 257,314 & 210,576 & 249,732 & 291,374 & 244,103 & 239,077 \\
\hline 3.1 & 256,265 & 194,563 & 235,923 & 286,159 & 309,019 & 271,578 \\
\hline 1.96 & 231,657 & 209,050 & 229,532 & 253,992 & 228,248 & 227,223 \\
\hline 3.13 & 231,378 & 144,298 & 179,945 & 217,862 & 239,014 & 193,588 \\
\hline 2.6 & 229,191 & 165,202 & 225,530 & 277,358 & 272,227 & 255,234 \\
\hline 1.23 & 224,456 & 198,763 & 239,656 & 270,633 & 212,795 & 214,957 \\
\hline 1.56 & 222,799 & 190,695 & 217,900 & 248,648 & 232,091 & 222,538 \\
\hline 3.12 & 219,583 & 182,666 & 215,754 & 252,547 & 230,062 & 224,544 \\
\hline 2.20 & 218,123 & 186,717 & 218,703 & 250,653 & 234,075 & 232,139 \\
\hline 2.21 & 216,611 & 189,453 & 222,823 & 251,154 & 215,941 & 215,426 \\
\hline 1.20 & 215,744 & 177,938 & 221,482 & 257,222 & 215,972 & 216,176 \\
\hline 1.79 & 206,694 & 167,564 & 199,582 & 233,461 & 233,030 & 208,246 \\
\hline 3.8 & 203,340 & 169,660 & 205,739 & 239,306 & 223,085 & 218,027 \\
\hline 5.1 & 195,615 & 160,613 & 194,396 & 229,571 & 243,174 & 225,305 \\
\hline 3.9 & 192,325 & 159,505 & 191,941 & 223,928 & 210,620 & 205,266 \\
\hline 1.72 & 192,225 & 146,318 & 192,367 & 226,098 & 223,058 & 213,516 \\
\hline 3.6 & 191,953 & 166,885 & 193,560 & 219,040 & 212,912 & 214,687 \\
\hline 1.31 & 191,830 & 157,614 & 190,105 & 222,799 & 196,569 & 196,303 \\
\hline 2.25 & 189,132 & 154,347 & 184,879 & 218,472 & 242,115 & 221,612 \\
\hline 1.67 & 181,745 & 143,332 & 181,622 & 213,853 & 196,210 & 186,829 \\
\hline 5.2 & 181,415 & 154,273 & 182,791 & 212,997 & 205,376 & 199,260 \\
\hline 1.101 & 178,708 & 161,172 & 182,779 & 213,839 & 202,614 & 198,277 \\
\hline 1.73 & 170,028 & 139,511 & 183,812 & 207,774 & 199,004 & 195,182 \\
\hline 1.54 & 164,446 & 131,857 & 166,579 & 199,279 & 123,409 & 186,378 \\
\hline 1.55 & 145,392 & 95,178 & 148,233 & 184,203 & 180,403 & 176,198 \\
\hline 3.7 & 134,150 & 76,353 & 138,176 & 182,299 & 191,052 & 194,655 \\
\hline Total & 201,561 & 151,927 & 196,964 & 241,250 & 200,689 & 195,403 \\
\hline
\end{tabular}

* Standardization consists in calculating the mean for all full time employed male between 35-45 years old. Mean age for all is 40 (s.d. 3.14) and lowest and highest mean among the clusters are 39.2 and 41.7.

** The discrepancies between the various income and wage measures in the 2.22 Manager cluster is due to the fact that there exist a small group of top income earners in the cluster, and the fact that much of the income is not from wage labour but from other sources like returns on capital. In fact, the highest incomes in this groups are not registered as full-time employed indicating that their income only to a limited extend comes from wage labour. 